\title{
THE ROLE OF PHAGOCYTOSIS-DEPENDENT ACTIVATION OF TFEB IN THE CLEARANCE OF SALMONELLA
}

\author{
By \\ Erika Ospina Escobar \\ Honours B.Sc. University of Guelph, 2013 \\ A thesis presented to Ryerson University \\ in partial fulfillment of the requirements for the degree of \\ Master of Science in the program of
}

Molecular Science

Toronto, Ontario, Canada, 2017

(C) Erika Ospina Escobar 2017 


\section{Author's Declaration}

I hereby declare that I am the sole author of this thesis. This is a true copy of the thesis, including any required final revisions, as accepted by my examiners.

I authorize Ryerson University to lend this thesis to other institutions or individuals for the purpose of scholarly research

I further authorize Ryerson University to reproduce this thesis by photocopying or by other means, in total or in part, at the request of other institutions or individuals for the purpose of scholarly research.

I understand that my thesis may be made electronically available to the public. 


\title{
Abstract \\ THE ROLE OF PHAGOCYTOSIS-DEPENDENT ACTIVATION OF TFEB IN THE CLEARANCE OF SALMONELLA
}

\author{
Erika Ospina Escobar \\ Master of Science, 2017 \\ Molecular Science, Ryeron University
}

During phagocytosis, macrophages engulf and sequester pathogens into phagosomes.

Phagosomes then fuse with acidic and degradative lysosomes to degrade the internalized pathogen. We previously demonstrated that phagocytosis of IgG-opsonized particles and nonopsonized E.coli causes activation of the Transcription Factor EB (TFEB), which enhances the expression of lysosomal genes, increases the degradative capacity of lysosomes and boosts bactericidal activity. However, pathogens like Salmonella typhimurium have evolved mechanisms to evade and/or alter phagosome maturation to promote their own survival. We investigated: i) whether pathogens like Salmonella can alter TFEB activation and ii) whether phagocytosis-dependent activation of TFEB can counteract the pathogenicity of microorganisms. Here, we show that non-viable (heat-killed) $S$. typhimurium, pathogenic (EHEC and UPEC) and non-pathogenic E.coli (DH5 $\alpha$ ) all caused TFEB nuclear translocation in RAW macrophages, while strikingly live $S$. typhimurium maintained TFEB in the cytosol in the first hours postinfection. By contrast, Salmonella mutants for $\triangle$ sifA, $\Delta s o p D 2, \Delta p h o P$ all triggered TFEB activation in the first hour of infection. However, Salmonella infection eventually triggered a steady increase in nuclear TFEB after $4 \mathrm{~h}$ of infection, suggesting a more complex interplay between TFEB and Salmonella infection. We dissected the importance of TFEB activation towards Salmonella survivability by pre-activating TFEB before infection within WT macrophages and macrophages with a CRISPR-based deletion of TFEB. Our work suggests that 
Salmonella actively interferes with TFEB signaling in order to enhance its own survival. These results could provide insight into using TFEB as a target for the clearance of infections. 
$I$ dedicate this work to my late grandfather,

\section{Luís Alfonso Escobar Cuenca}

$$
(1929 \text { - 2017) }
$$




\section{Acknowledgements}

This journey would not have been possible without the guidance and help of several people, who in one way or another have contributed to the completion of my studies.

First, I would like to acknowledge my supervisor, Dr. R. Botelho, for his patience, guidance and encouragement through these past two years of this project. His door was always open for questions and concerns and I am profoundly thankful for his mentorship, time and support, but most importantly for the challenges that have steered me in the right direction and helped broaden my knowledge.

I would also like to thank my supervisory committee members, Dr. Sarah Sabatinos and Dr. Joseph McPhee for their time and support, but mainly for providing me invaluable feedback through this challenging, yet unforgettable process.

To Dr. Matthew Gray, thank you for mentoring me through these past two years and for guiding me with the experiments required for the completion of this thesis.

To Zechariah Martin, thank you for being a great friend, for listening and for your endless encouraging words. Thank you for daily inspirational quotes and much needed coffee breaks.

Finally, I must express my profound thanks to my parents and sister for their constant love, emotional and moral support towards the completion of this thesis. Thank you for encouraging me in all my pursuits and inspiring me to follow my dreams. I hope that I have made you proud. 
Last but not least, to my boyfriend, thank you for being so supportive, for being patient, and for constantly encouraging me through every step of the way. 
Table of Contents

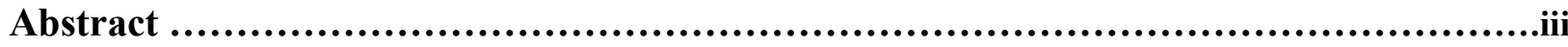

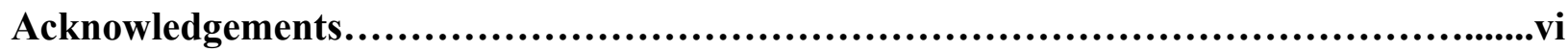

Table of Contents............................................................................iii

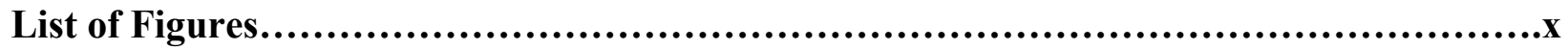

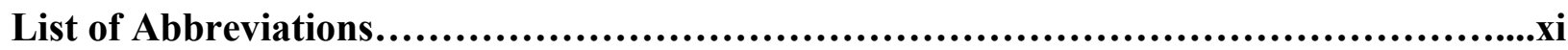

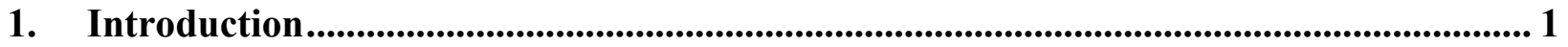

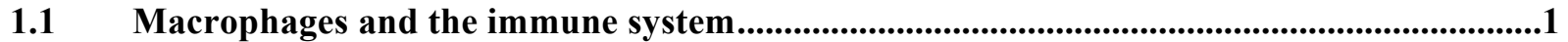

1.2 The biology and importance of macrophages ......................................................................1

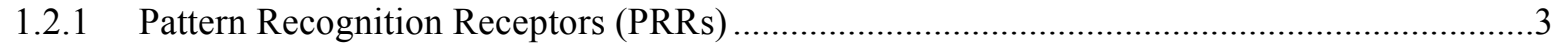

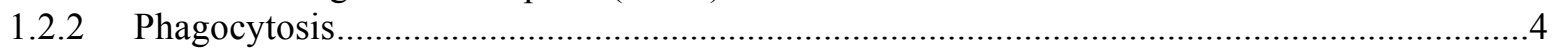

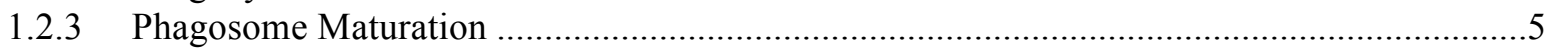

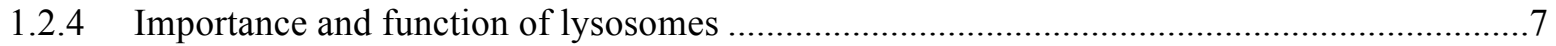

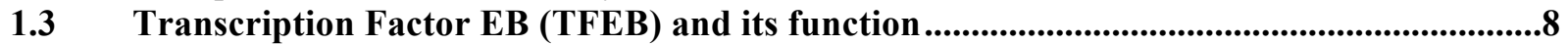

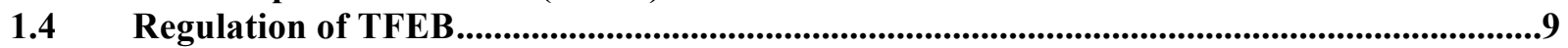

1.5 Salmonella enterica Serovar Typhimurium (S. typhimurium) infection and progression .14

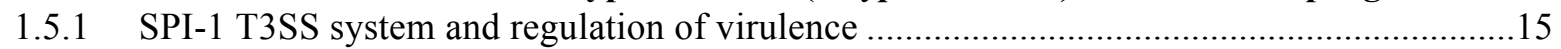

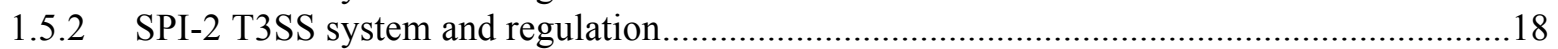

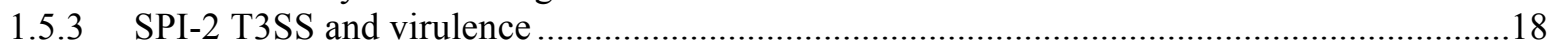

1.6 Pathogenic infections and TFEB-mediated clearance of infection .....................................21

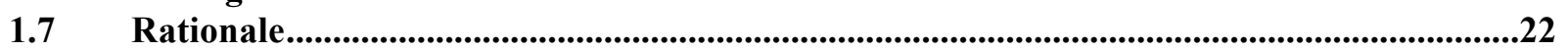

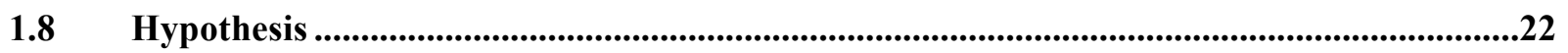

2. Experimental Procedures ............................................................................................ 23

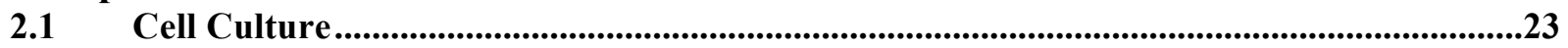

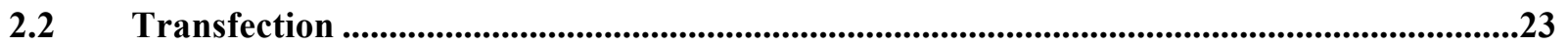

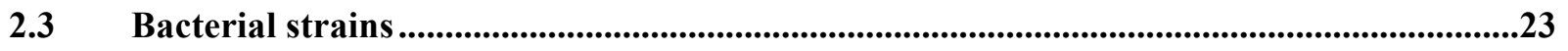

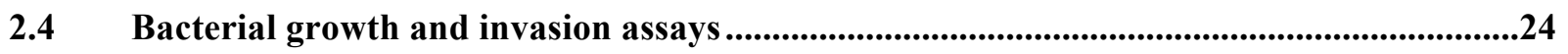

2.5 Bacterial survival assay and gentamicin protection assays .................................................24

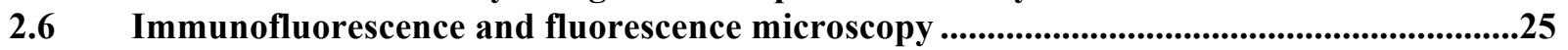

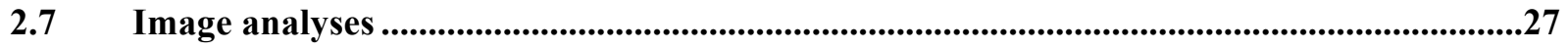

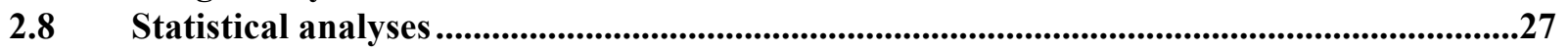

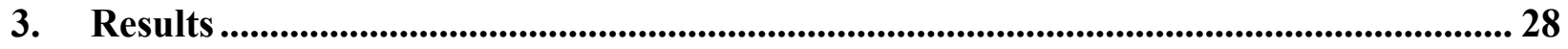

3.1 Phagocytic uptake of non-opsonic pathogenic E.coli activates TFEB nuclear translocation 28

3.2 Salmonella typhimurium actively manipulates TFEB cellular localization.........................31

3.3 Salmonella manipulates TFEB in a time-dependent manner...............................................34

3.4 Growth conditions affect Salmonella's way of interacting with the host..............................36

3.5 SPI-2 effector defects in Salmonella promote TFEB nuclear translocation .........................38

3.6 TFEB is required for lysosomal-based degradation of bacteria .............................................44

3.7 TFEB pre-activation makes macrophages better killers ............................................................47

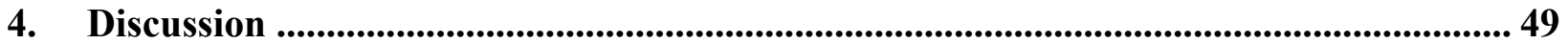

4.1 Summary of findings .................................................................................................................... 
4.2 Pathogenic and non-pathogenic $E$. coli activate TFEB

4.3 Salmonella must be alive to prevent TFEB nuclear localization...........................................50

4.4 Salmonella regulates TFEB in a time and growth-dependent manner. ...............................51

4.5 SPI-2 expression plays an important role on TFEB repression ..............................................55

4.6 TFEB is important for bacterial degradation .......................................................................57

4.7 TFEB pre-activation increases the chances of clearance of infection..................................58

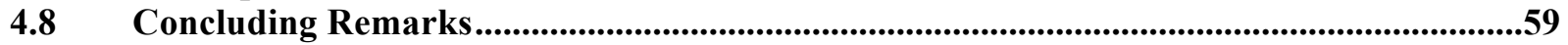

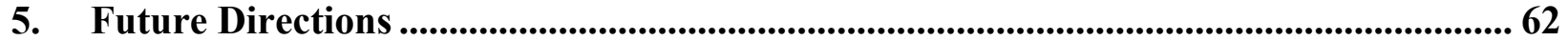
5.1 Determine the mechanisms of action by which Salmonella interferes with TFEB

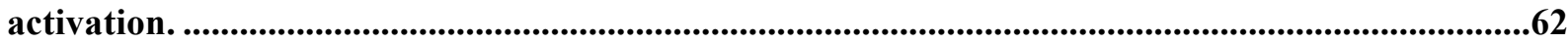

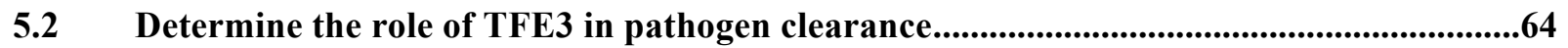

5.3 In vivo function of TFEB in the clearance of infections ..................................................65

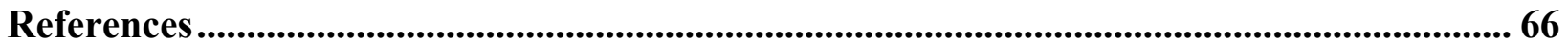




\section{List of Figures}

$\begin{array}{lr}\text { Figure 1. Phagosome maturation. } & 6\end{array}$

$\begin{array}{lr}\text { Figure 2. Schematic representation of TFEB activation. } & 12\end{array}$

Figure 3. Schematic representation of TFEB regulation by mTORC1. 13

Figure. 4. Regulation of SPI-1 expression by two-component regulatory systems. 17

Figure 5. Salmonella SPI-2 virulence and regulation. 2

Figure 6. Phagocytosis of non-opsonized pathogenic and non-pathogenic E.coli causes

TFEB nuclear translocation in TFEB-GFP transfected cells. 29

Figure 7. Salmonella typhimurium actively prevents TFEB activation. 32

Figure 8. TFEB nuclear translocation is greater at later time-points of Salmonella

$\begin{array}{ll}\text { infection. } & 35\end{array}$

Figure 9. Salmonella growth conditions affect TFEB subcellular location. 37

Figure 10. Identification of Salmonella mutants that lose the ability to block TFEB-GFP

nuclear translocation in transfected RAW 264.7 macrophages.

Figure 11. Identification of Salmonella mutants that fail to block TFEB in non-transfected

$\begin{array}{ll}\text { cells. } & 42\end{array}$

Figure 12. TFEB is necessary for bacterial clearance. 46

Figure 13. TFEB pre-activation increases the macrophage's ability to clear infections. $\quad 48$

Figure 14. SPI-2 T3SS plays an important, yet partial role in the repression of TFEB

$\begin{array}{ll}\text { activation. } & 54\end{array}$

Figure 15. Suggested final model of TFEB regulation by Salmonella. 61 


\section{List of Abbreviations}

AKT- v-akt murine thymoma viral oncogene

BMDM - Bone-marrow derived macrophages

bHLH - Basic Helix -Loop-Helix

AMPK - Adenosine Monophosphate Kinase

CFU- Colony Forming Unit

CLEAR - Coordinated Lysosomal Expression and Regulatory network

CRISPR - Clustered Regularly Interspaced Short Palindromic Repeats

DKO - Double-knockout

DMEM - Dulbecco's Modified Eagle's Medium

EE - Early Endosome

EP - Early Phagosome

EHEC - Enterohemorragic Escherichia coli

ERK2 - Extracellular-Regulated Kinase 2

FBS - Fetal Bovine Serum

Fc $\gamma \mathbf{R}$ - Fc gamma Receptor

GPA - Gentamicin Protection Assay

gRNA - Guide RNA

IFN $\gamma$ - Interferon- $\gamma$

IgG - Immunoglobin G

KO - Knock-Out

LAMP-1 - Lysosomal Associate Membrane Protein 1 
LAMP-2 - Lysosomal Associate Membrane Protein 2

LB - Lysogeny Broth

LE - Late Endosome

LKB1 - Liver Kinase B1

LP - Late Phagosome

LPS - Lipopolysaccharides

LSDs - Lysosomal Storage Diseases

LTA - Lipoteichoic Acid

LZ - Leucine Zipper

MAMPS - Microorganism Associated Molecular Patterns

MHC- Major Histocompatibility Molecule

Mit - Micropthalmia

MOI - Multiplicity of Infection

mTORC1 - Mammalian Target of Rapamycin Complex 1

NIH - National Institute of Health

OB - Opsonized Beads

P.I - Post Infection

PAI - Pathogenicity Island

PAMPs - Pathogen Associated Molecular Patterns

PBS - Phosphate-Buffered Saline

PFA - Paraformaldehyde

PKC $\boldsymbol{\beta}$ - Protein Kinase C isoform $\beta$

PL - Phagolysosome 
PRRs - Pattern Recognition Receptors

SCVs - Salmonella Containing Vacuoles

SIFs - Salmonella-Induced Filaments

Sirt-1 - Sirtuin-1

SPI-1 - Salmonella Pathogenicity Island 1

SPI-2 - Salmonella Pathogenicity Island 2

Stxs - Shiga toxins

T3SS - Type III Secretion System

TFE - Transcription Factor E

Th - T helper cells

TLR4 - Toll-Like Receptor 4

TLRs - Toll-like Receptors

TRPML1 - Transient Receptor Potential Mucolipin 1

UPEC - Uropathogenic Escherichia coli

WT - Wild-Type 


\section{Introduction}

\subsection{Macrophages and the immune system}

All living organisms are prone to attacks by disease-causing agents present in the environment. To tackle this problem, humans have a complex group of cells and tissues that form the immune system and work together to protect us against dangerous and foreign bodies like antigens, pathogens, cancer cells and toxins(Janeway, 2001). The first line of defense against microbes are the physical and chemical barriers that include the skin, tears, mucus, stomach acid and many more. If the physical barrier gets penetrated, the second line of defense is activated and consists of a group of cells that are recruited to the site of infection in what is called an immune response (Warrington, Watson, Kim, \& Antonetti, 2011). Various types of cells are involved in the immune response including dendritic cells (DCs), neutrophils and macrophages (Warrington et al., 2011). These cells are called phagocytes due to their ability to engulf and kill microbes, remove dead cells, and debris. While neutrophils are the most abundant and the first cells to arrive to the site of infection, they are short-lived compared to macrophages and DCs (Warrington et al., 2011).

\subsection{The biology and importance of macrophages}

Macrophages are mononuclear cells derived from bone-marrow precursors that differentiate into monocytes and circulate in the blood. They are professional phagocytic cells found in all body tissues, where they are constantly keeping surveillance of the immune system for any signs of infection and foreign invaders (Stanley \& Lacy, 2010). In the $19^{\text {th }}$ century, Ellie Metchnikoff described them as the "police" of the organism, fighting against invading pathogens 
and injuries, but also as the "janitor" of the organism, cleaning and removing dying cells, cellular debris, and also involved in removing bacteria and their own damaged organelles (Tauber, 2003). They are responsible for the clearance of infections, garbage disposal and antigen presentation (Warrington et al., 2011). Macrophages function as the control switch of the immune system, keeping a balance between pro versus anti-inflammatory response. Upon infection or injury, macrophages are recruited to the site of infection, where they are either classically ('M1') or alternatively ('M2') activated, allowing them to carry out different defensive functions. M1 macrophages have a greater killing/inhibitory capacity displaying a cytotoxic and pro-inflammatory phenotype. M1 macrophages are stimulated by type I cytokines like interferon- $\gamma(\mathrm{IFN} \gamma)$ or tumor necrosis factor- $\alpha(\mathrm{TNF} \alpha)$. These cytokines are released following recognition of pathogen associated molecular patterns (PAMPS) or microorganism associated molecular patterns (MAMPS) found on the cell surface of microorganisms, or by “danger" signals like heat shock proteins (Laskin, 2009). On the other hand, M2 polymerized macrophages have a greater role in the healing and growth of cells by suppressing immune and inflammatory responses, yet, facilitating wound repair and angiogenesis. They are activated by fungal cells, parasites, immune complexes, complement molecules, apoptotic cells and others (Italiani \& Boraschi, 2014). M1 macrophages are present at the early stages of infection, engulfing pathogens and breaking them down into antigenic peptides. These antigenic peptides get displayed at the surface of the cell within a major histocompatibility molecule (MHC) to be recognized by helper $\mathrm{T}$ cells $(\mathrm{Th})$ in a process called antigen-presentation. Th cells release cytokines that activate 'M2' macrophages to further help in the phagocytosis of the pathogens and B cells, proliferate and produce antibodies for a greater inflammatory response (Janeway, 2001; Laskin, 2009). The classification of 'M1/M2' macrophages oversimplifies their 
functionality, since the same cells can take place in the pro-inflammatory and cytotoxic process, and later help in the resolution of inflammation and clearance of infection (Italiani \& Boraschi, 2014; Laskin, 2009). Macrophages are a great model for investigating the role of phagocytosis in immunity and infection due to the complex and variety of different roles they play in the immune response.

\subsubsection{Pattern Recognition Receptors (PRRs)}

Macrophages express a wide variety of surface receptors called pattern recognition receptors (PRRs) that allow for receptor-ligand engagement at the cell membrane (Sansonetti, 2001). PRRs on the cell surface of macrophages and other professional phagocytic cells are capable of sensing the presence of invaders through the recognition of conserved structures like PAMPs or MAMPs (Newman, Sundelin, Nielsen, \& Erbs, 2013; Vural \& Kehrl, 2014). The host cell has three advantages to PAMPs/MAMPs recognition. First, they are only produced by microbes and not host cells, allowing the immune system to distinguish between foreign and self. Second, they are essential for survival of microbes with mutations in or loss of molecules that display these conserved molecular patterns leading to lethality for the microbe; therefore, PAMPs/MAMPs tend to be highly conserved through evolution. Third, PAMPs/MAMPs are invariant between microorganisms of a given class, which tells us that only a limited number of PRRs are needed to detected the presence of a wide variety of microbial species (Janssens \& Beyaert, 2003). An example of these conserved components include lipopolysaccharides (LPS) and lipoteichoic acid (LTA), which are found on the cell walls of gram-negative and grampositive bacteria, respectively (Aderem, 2003). These components are recognized by the most important members of the PRRs family, the Toll-like receptors (TLRs), TLR4 and TLR2, in that 
order. TLRs rely on the recruitment and activation of intracellular molecules and kinases to pass on their signaling cascade to alert the host of the presence of infection. This ultimately leads to pathogen and/or particle internalization and anti-microbial response through phagocytosis (Janssens \& Beyaert, 2003; Mogensen, 2009).

\subsubsection{Phagocytosis}

Phagocytosis can be separated into two major groups: opsonic and non-opsonic phagocytosis (Cabec et al., 2017). Non-opsonic phagocytosis refers to phagocytosis through non-opsonic receptors, such as TLRs, that recognize specific ligands on microorganisms destined for degradation. Whereas opsonic phagocytosis refers to the ligand-receptor recognition of foreign particles or pathogens that are coated with defense host proteins (opsonins) that demarcate the particle for phagocytosis and degradation (Botelho \& Grinstein, 2011; Murray \& Wynn, 2011). An example of these opsonins is immunoglobin $\mathrm{G}(\mathrm{IgG})$, which coats particles (IgG-opsonized particles) and is recognized by Fc-gamma receptors ( Fc $\gamma \mathrm{R})$ expressed on macrophages (Gray et al., 2016). Phagocytosis begins by a receptor-ligand interaction at the cell surface, which generates various signaling cascades that allow for the internalization of large ( $\geq$ $0.5 \mu \mathrm{m}$ ) particles into membrane-derived vacuoles called phagosomes (Botelho \& Grinstein, 2011). These phagosomes go through phagosome maturation preparing the vacuole for degradation and at the same time promoting an inflammatory response. 


\subsubsection{Phagosome Maturation}

Following detachment of the phagosome from the plasma membrane, the lumen of the nascent phagosome mimics the extracellular environment and has a neutral $\mathrm{pH}$ (Botelho \& Grinstein, 2011). Once inside the host cell, the phagosome undergoes a variety of changes through a process called phagosome maturation, acquiring different phagosomal markers along the way (Botelho \& Grinstein, 2011). During phagosome maturation, the nascent phagosome progressively starts to acquire microbicidal and degradative characteristics by fusing with members of the endocytic pathway like the early endosomes (EEs), late endosomes (LEs) and lysosomes, forming early phagosomes (EPs), late phagosomes (LPs) and phagolysosomes (PLs), respectively (Haas, 2007). It is during his process that the phagosome is further acidified to a $\mathrm{pH}$ of approximately 4.7, thus fully activating the degradative enzymes delivered through lysosomal fusion(Botelho \& Grinstein, 2011; Fairn \& Grinstein, 2012; Lu \& Zhou, 2013). The combined effects of acidification and the activity of degradative enzymes results in the demise and degradation of internalized cargo (Fig. 1). 


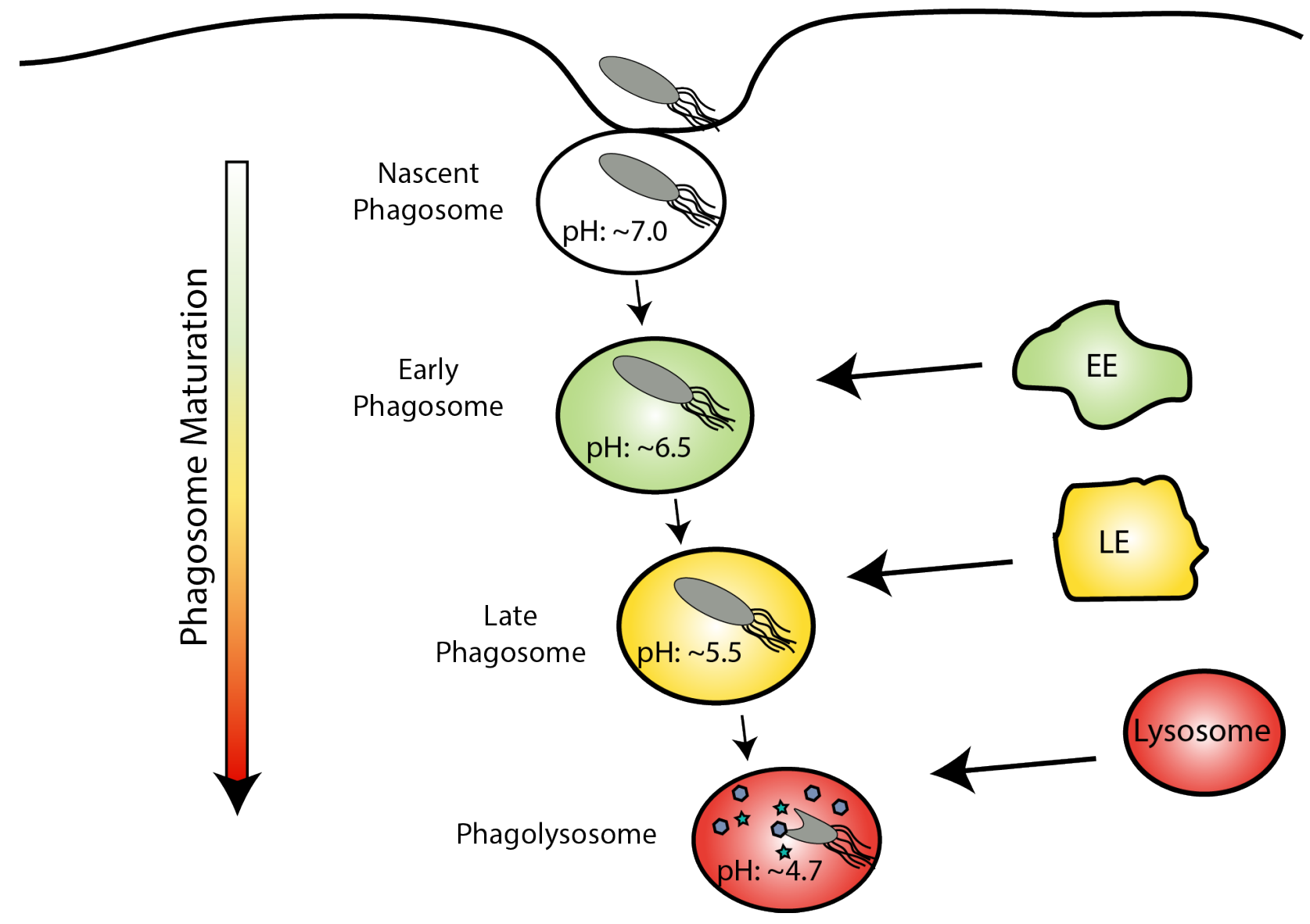

Figure 1. Phagosome Maturation. Following internalization of the cargo into a phagosome, the nascent phagosome undergoes a series of fusion events with the members of the endocytic pathway, acquiring phagosomal markers and a more digestive/acidic environment along the way, giving rise to the phagolysosome. At this later stage, the phagosome obtains hydrolases that are activated due to the acidic environment, and this allows for the degradation of the internalized cargo (Main idea was obtained from Botelho and Grinstein, 2011). 


\subsubsection{Importance and function of lysosomes}

Lysosomes are membrane-bound organelles that function as the 'stomach' or 'recycling centre of the cell. They contain more than 60 enzymes, such as phosphatases, nucleases glucosidases, proteases, acid phosphatases, sulfatases and lipases (Settembre, Fraldi, Medina, Ballabio, \& Children, 2015). These enzymes work together to break down all types of biological macromolecules including proteins, nucleic acids, lipids, carbohydrates, they also degrade damaged organelles and bacteria. Lysosomes vary in size and shape, but have a highly acidic lysosomal lumen ranging between a $\mathrm{pH}$ of 4.5-4.7, required for the optimal activity of the enzymes (Appelqvist, Wäster, Kågedal, \& Öllinger, 2013). The acidic environment in the lysosomes is maintained by membrane bound proteins, like the vacuolar ATPase (v-ATPase), which pumps protons $\left(\mathrm{H}^{+}\right)$from the cytosol into the lysosome maintaining the proper $\mathrm{pH}$ for enzyme functioning (Ishida, Nayak, Mindell, \& Grabe, 2013). Certain proteins that are associated with late-endosomes/lysosome like the GTPase Rab7, play an important role in lateendosome membrane fusion by interacting with SNARE ( $N$-ethlymaleimide-sensitive fusion protein attachment receptor). Rab7 also plays a role in membrane trafficking to the lysosomes, which is accomplished by associating with Rab-interacting lysosomal protein (RILP) that is important in the targeting of Rab7 containing organelles to the motor complex (Cantalupo, Alifano, Roberti, Bruni, \& Bucci, 2001). Thus, Rab7 is a key protein in the biogenesis of phagolysosomes and their subsequent acquisition of microbicidal characteristic for lysosomal degradation. Notably, subversion of Rab-7-mediated trafficking machineries by pathogens, often leads to the avoidance of degradation (D'Costa et al., 2015). Lysosomes also contain lysosomal membrane proteins that are important for trafficking and motility, integrity of the lysosome, lysosomal exocytosis and structure, with the most abundant proteins being lysosomal associated 
membrane protein 1 and 2 (LAMP-1 and LAMP-2) (Schwake \& Schr, 2013). Lysosomes are terminal organelles for many processes that require degradation of macromolecules, pathogens, dead cells, and obsolete organelles, this includes endocytosis, phagocytosis and autophagy, therefore their presence and regulation is very important to maintain harmony within a cell. The molecular machinery behind lysosomal function and its regulation has been linked to a network of genes called coordinated lysosomal expression and regulatory network (CLEAR) for the presence of a CLEAR sequence (GTCACGTGAC) near the transcription start site (Palmieri et al., 2011). Lysosomes were thought to be static organelles, but recent discoveries have linked their up and/or down-regulation to transcription factor EB (TFEB).

\subsection{Transcription Factor EB (TFEB) and its function}

Transcription factor EB is a member of the micropthalmia-trascription factor $\mathrm{E}$ (MiTF/TFE) subfamily, which in turn is part of a larger family characterized by the presence of adjacent a basic helix-loop-helix (BHLH) and leucine-zipper (LZ) domains (Fisher, Carr, Parent, \& Sharp, 1991; Fisher, Parentt, \& Sharpt, 1992). TFEB's efficient DNA-binding requires dimerization with itself or with another MiTF/TFE family member, like TFE3 or MiTF. Deletion of the basic domains of these transcription factors renders them incapable of DNA binding (Fisher et al., 1991). It is known that members of MiTF/TFE family specifically binds to E-box (“CANNTG”) and/or M-box (AGTCATGTGCT) response elements presented in the promoter regions of their downstream targets (Jose A Martina, Diab, Huiqing, \& Puertollano, 2015). TFEB and the family member, TFE3, were identified as a protein that binds and activate transcription through the immunoglobulin heavy-chain enhancer $\mu \mathrm{E} 3$ motif and together are implicated in humoral immunity (Beckman \& Kadeseh, 1991; Fisher et al., 1992). Although there's not a lot 
known about the specifics of TFEB-DNA binding mechanism, it is noted that TFEB induces a minor-groove-oriented bending of DNA, possibly to facilitate transcription (Fisher et al., 1992). In the last few years, TFEB has been identified as one of the key regulators of the CLEAR network, but more importantly, as the transcriptional modulator of the lysosomal system (Palmieri et al., 2011; Palmieri, Pal, \& Sardiello, 2017; Settembre, C,, Di malta C., Polito VA, Garcia Arencibia, Vetrini F, Erding S, 2012; Settembre et al., 2010). TFEB can enter the nucleus of cells directly inducing the expression of genes by binding to the CLEAR sequence at their promoter region (Nabar \& Kehrl, 2017; Palmieri et al., 2011).

\subsection{Regulation of TFEB}

TFEB has been studied over the years, but just recently more is being understood about the complexity of its regulation. Under resting conditions when nutrients are plentiful, TFEB is localized in the cytosol of the cell as a result of phosphorylation by the mammalian target of rapamycin complex 1 (mTORC1) and extracellular-regulated kinase 2 (ERK2). mTORC1 gets

recruited to the lysosomal membrane and phosphorylates TFEB at $\operatorname{Ser}^{211}$ and $\operatorname{Ser}^{142}$ positions (S. G. Kim, Buel, \& Blenis, 2013; José A Martina \& Puertollano, 2016; Pastore et al., 2016; PenaLlopis et al., 2011). Phosphorylation at the $\operatorname{Ser}^{211}$ position creates a binding site for proteins 143-3, which bind a multitude of signaling proteins, including kinases, phosphatases and transmembrane proteins involved in the regulation of intracellular signaling. In this case, 14-3-3 acts as a cytosolic chaperone that is in charge of retaining TFEB in the cytosol (Fig. 3) (José A Martina \& Puertollano, 2016). In 2011, Settembre et al., showed that ERK2 also interacts with TFEB by phosphorylating it at $\operatorname{Ser}^{142}$ site in normal but not starved conditions, although later indicated that ERK2 phosphorylation of TFEB seems to be only partially responsible for its cytosolic retention, and suggesting that mTOR-mediated regulation of TFEB is predominant 
(Settembre et al., 2012). Conversely, under stressful conditions, that include starvation, lysosomal stress and infection, TFEB is activated through different mechanisms that are still being studied. The first mechanism is the regulation of TFEB by calcineurin PPP3CB (calcineurin catalytic subunit isoform beta) (Nabar \& Kehrl, 2017; Pastore et al., 2016). During starvation or stress, mTORC1 disassociates from the lysosomal membrane preventing TFEB phosphorylation, at the same time, $\mathrm{Ca}^{2+}$ released via the mucolipin 1/TRPML1 (transient receptor protein mucolipin 1) channel on the lysosomal membrane during phagosome-lysosome fusion, interacts with calcineurin, which then dephosphorylates TFEB at $\mathrm{Ser}^{211}$. This then enables TFEB nuclear translocation and expression of lysosomal and autophagy genes (Gray et al., 2016; Nabar \& Kehrl, 2017; Sardiello, 2016). It has also been suggested that dephosphorylation at Ser ${ }^{142}$ mediates TFEB nuclear translocation by reducing the phosphorylation at $\mathrm{Ser}^{211}$, although the exact mechanism is still not clear (Nabar \& Kehrl, 2017). The second method that leads to TFEB activation is through the PLC-PKD pathway during infection (Najibi, Labed, Visvikis, \& Irazoqui, 2016). Pathogens activate the pathway by interacting with an unknown receptor, followed by a signaling cascade that leads to the activation of TFEB by serine/threonine protein kinase $\mathrm{D}(\mathrm{PKD}) / \mathrm{PKC}$. Another article indicates that PKD1 is activated by TLRs in a MyD88 dependent manner, leading to the expression of pro-inflammatory cytokines and mediators in the immune response (Y. Kim, Park, \& Brand, 2010). TFEB regulation involves various pathways and it seems to be rather complex (Fig. 2), illustrating the importance in understanding its role in the immune response. It is known that cells overexpressing TFEB have a larger number of lysosomes and possess an enhanced degradative capability (Gray et al., 2016; Sbano et al., 2017). This allows us to examine the potential for TFEB-mediated lysosomal enhancement in the treatment of degenerative storage diseases, like lysosomal storage diseases (LSDs) and the 
potential therapeutic use in the clearance of bacterial infections (Gray et al., 2016; Palmieri et al., 2011; Palmieri, Pal, \& Sardiello, 2017; Settembre et al., 2012). 


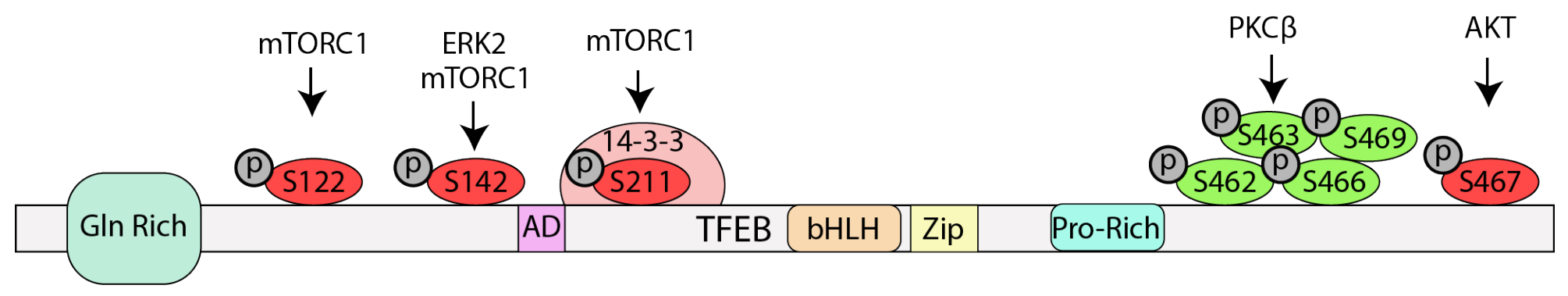

Figure 2. Schematic representation of TFEB activation. TFEB is phosphorylated at different serine sites by a diverse number of kinases. Phosphorylation by mTORC1, ERK2 and AKT are inhibitory (Red), preventing TFEB translocation to the nucleus, whereas phosphorylation by Protein Kinase $\mathrm{C}$ isoform $\beta$ (PKC $\beta$ ) activates TFEB nuclear translocation (Green). (Main idea obtained from Nabar and Kehrl, 2017) 


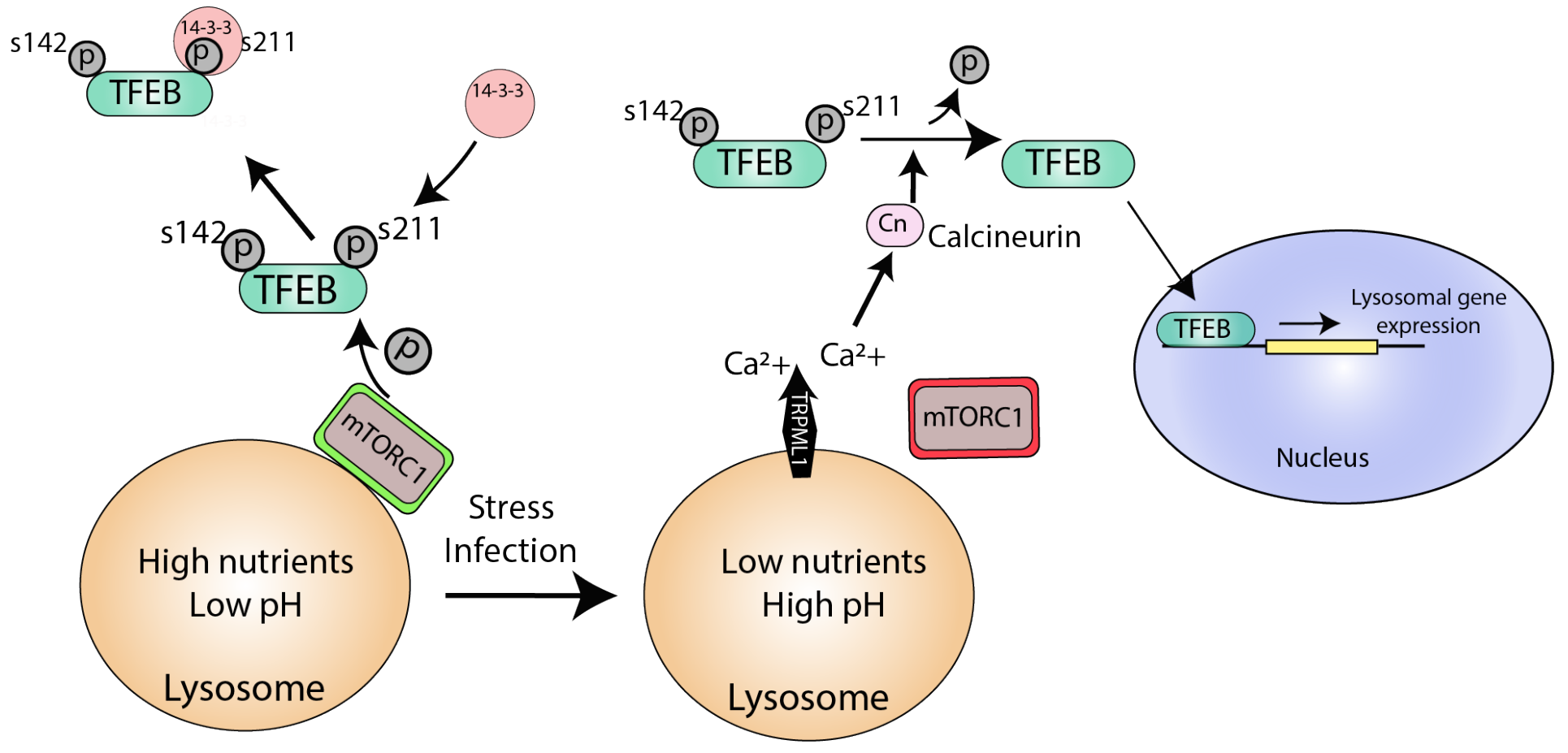

Figure 3. Schematic representation of TFEB regulation by mTORC1. This diagram summarizes how mTORC1 controls the subcellular localization of TFEB. Active mTORC1 localizes to the lysosomal membrane and its able to phosphorylate TFEB at $\operatorname{Ser}^{142}$ and $\operatorname{Ser}^{211}$ residues, this phosphorylation allows for the cytosolic retention of TFEB by 14-3-3. The inactivation of mTORC1 allows for the activation of TFEB, through the release of $\mathrm{Ca}^{2+}$ from the lysosome, followed by dephosphorylation of TFEB and its subsequent nuclear translocation. 


\subsection{Salmonella enterica Serovar Typhimurium (S. typhimurium) infection and progression}

S. typhimurium (herein Salmonella) is a gram-negative intracellular pathogen capable of causing a wide range of illnesses in a variety of host organisms. The symptoms include mild food poisoning to life threatening-systemic infections (Jorge E Galan, 2001). Salmonella can be ingested through contaminated food or water, and once inside, it colonizes the gastrointestinal tract; in general, a high inoculum is required to overcome the acidic $\mathrm{pH}$ of the stomach (Wisner, Desin, White, Potter, \& Köster, 2012). Salmonella can invade host cells in two different ways. The first method, involves binding and uptake into phagocytic cells that is facilitated by the recognition of the lipid A component on the salmonella's outer membrane component, lipopolysaccharide (LPS), a PAMP/MAMP, whose recognition and binding to TLR4 is facilitated by a complex set of proteins, LPS binding protein (LBP), CD-14 and MD-2 (Vural \& Kehrl, 2014; Wisner et al., 2012). The second method is more complex and it involves a series of events and actions of the Salmonella Pathogenicity Island I (SPI-1) Type 3 Secretion System T3SS on non-phagocytic cells triggering cell membrane "ruffling" and cytoskeleton rearrangement to get internalized (Wisner et al., 2012). Once inside the host cell through either mechanism, the bacteria is encased within a Salmonella-containing vacuole (SCV) that undergoes phagosome maturation. While the goal of many intracellular pathogens including Salmonella, is to escape the SCV and replicate within the cytosol of the host, Salmonella is also able to use this capsule and its hostile environment for its own advantage and survival (Mitchell, Chen, Portnoy, \& Biology, 2016; Wisner et al., 2012). To establish infection, Salmonella uses virulence factors expressed at different stages of infection, these factors or effectors are released via a T3SS (D'Costa et al., 2015). T3SS acts as 'injectosomes' and they are used by the bacteria to inject or deliver effector proteins into the host cells. In Salmonella, these T3SS systems are 
encoded by Pathogenicity Islands (PAIs), which contain large clusters of virulence genes that act together with a complex role in pathogenicity (Wisner et al., 2012). Salmonella encodes two injectosomes critical for their pathogenesis and progression, Salmonella Pathogenicity Island 1 and 2 (SPI-1 and SPI-2), essential for host invasion and survival, respectively (Chakravortty, Rohde, Jäger, Deiwick, \& Hensel, 2005; J E Galan, Ginocchio, \& Costeas, 1992; Torraca, Masud, Spaink, \& Meijer, 2014; Wing, Yan, Goldman, \& Goldberg, 2004; Zhao et al., 2015). The SPI-1 is $38.8 \mathrm{~kb}$ in length, whereas the latter one is $39.8 \mathrm{~kb}$. Both loci contain genes encoding a T3SS structural genes, T3SS regulatory genes and T3SS effectors (Wee \& Hughes, 2015).

\subsubsection{SPI-1 T3SS system and regulation of virulence}

SPI-1 T3SS is essential for Salmonella invasion of the intestinal epithelium. The engine of this "complex" T3SS is a set of proteins involved in the making of the needle-like structure that work together to deliver SPI-1 effectors into the host cell. These effectors cause physiological changes that include actin rearrangements, leading to the uptake of bacteria by non-phagocytic epithelial cells or Salmonella-induced necrosis in macrophages (Wisner et al., 2012; Zhou \& Galán, 2001). Salmonella requires expression of SPI-1 T3SS only at a particular stage of infection; therefore its regulation is tightly controlled by various inputs (Pavlova et al., 2011; Wisner et al., 2012). SPI-1 expression is controlled by a variety of environmental signals and the level of the transcriptional master regulator HilA (C. D. Ellermeier, Ellermeier, \& Slauch, 2005). HilA directly activates transcription of genes that lead to the secretion of the SPI1 effectors (C. D. Ellermeier et al., 2005; Wisner et al., 2012). The two component regulatory systems, PhoP/PhoQ and BarA/SirA, respond to environmental conditions such as the 
concentration of magnesium and phosphate, respectively (Wisner et al., 2012). They consist of a membrane sensor kinase and a cytoplasmic response regulator protein. The sensor reacts to various environmental signals, causing its autophosphorylation and activation of the response regulator, which in turn, activates or represses the expression of downstream proteins/molecules. For example, in low magnesium conditions, or when the Salmonella is within the SCV, PhoP can negatively regulate HilA, leading to the down-regulation of SPI-1 T3SS. Whereas, SirA positively regulates HilA by regulating the expression of HilD when the Salmonella is in nutrient rich environments, such as the environment of the small intestine, therefore inducing the expression of SPI-1 T3SS and promoting host invasion (Fig. 4) (C. D. Ellermeier et al., 2005; J. R. Ellermeier \& Slauch, 2007; Wisner et al., 2012). 


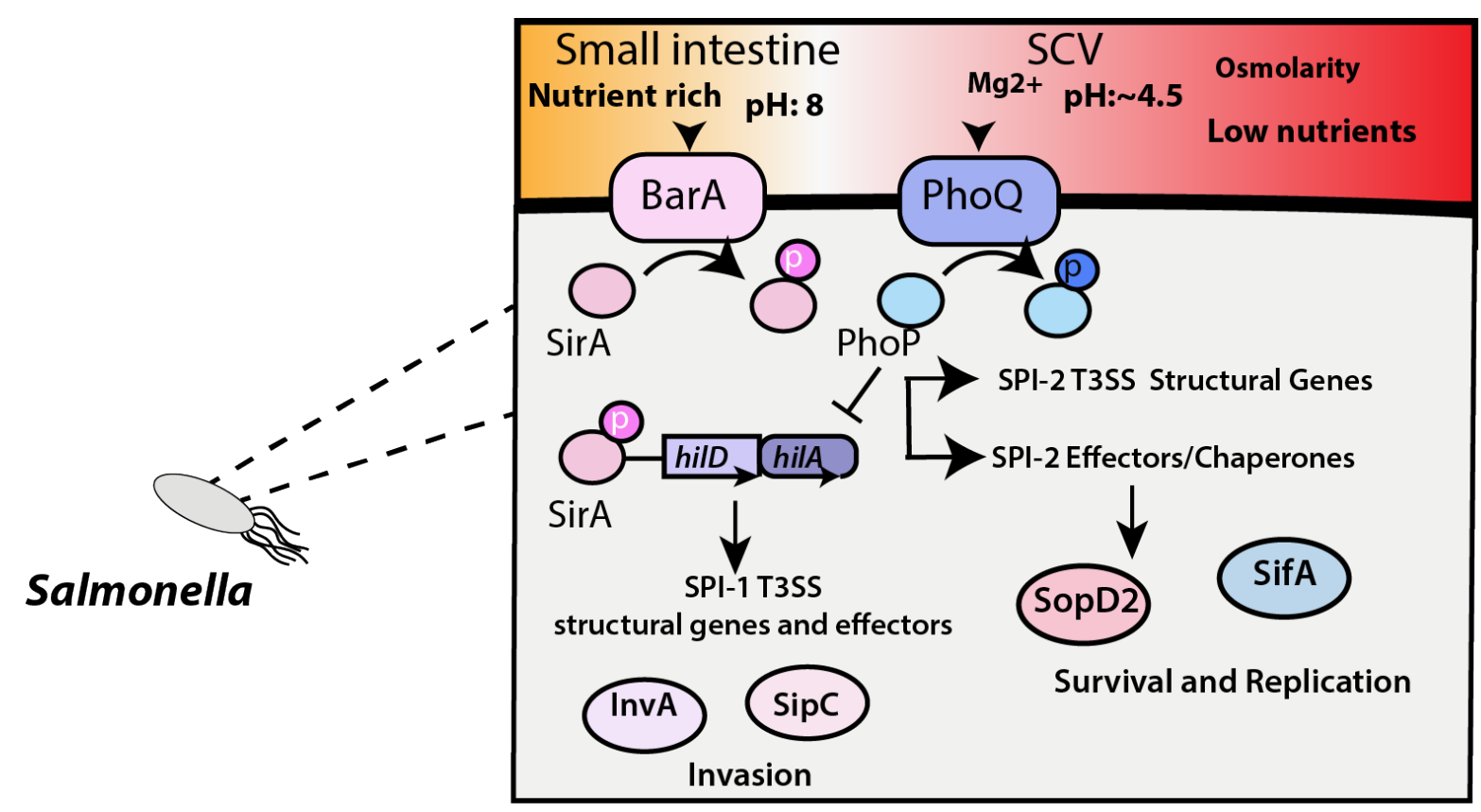

Figure. 4. Regulation of SPI-1 expression by two-component regulatory systems. SPI-1 T3SS and effectors are needed for Salmonella invasion of epithelial cells. This is a schematic representation of SPI-1 structural genes and effectors regulated by BarA/SirA and PhoP/PhoQ two component regulatory systems. PhoP is responsible for the transition from SPI-1 T3SS expression to SPI-2 T3SS expression, essential for the virulence of salmonella. 


\subsubsection{SPI-2 T3SS system and regulation}

SPI-2 is also a T3SS that is tightly regulated and essential for the survival of Salmonella within SCV and the systemic phase of infection (Wisner et al., 2012). Similar to the SPI-1 system, it assembles a needle-like structure upon recognition of environmental and genetic signals (van der Velden, Lindgren, Worley, \& Heffron, 2000; Wisner et al., 2012). As with SPI-1 T3SS, the SPI-2 T3SS is affected by the surroundings of the Salmonella, in this case the SCV environment, detected by the global two-component regulatory systems, PhoP/PhoQ and EnvZ/OmpR. PhoP/PhoQ is said to be the master regulator for the transition from the extracellular to the intracellular lifestyle of the pathogen by inducing expression of genes associated with intracellular Salmonella, and repressing the expression of SPI-1 via HilA (Fig. 4) (Groisman, 2001). PhoQ senses the SCV environment (low $\mathrm{Mg}^{2+}$, low $\mathrm{Ca}^{2+}$, antimicrobial peptides and a high $\mathrm{pH}$ ) phosphorylating and activating PhoP to bind to $\operatorname{ss} B$ and regulate the expression of $\operatorname{ss} A B$, another two-component regulatory system, which is essential for the induction of SPI-2 T3SS and its effector proteins (Garmendia, Beuzón, Ruiz-Albert, \& Holden, 2003). Whereas OmpR binds to both $s s r A$ and $\operatorname{ss} B$ promoters, directly activating transcription of SPI-2 T3SS components and SPI-2 effector proteins, essential to maintain control of the intracellular environment of the Salmonella as well as that of the host (Fig. 5) (Bijlsma \& Groisman, 2005; Forest, Ferraro, Sabbagh, \& Daigle, 2010; Hensel, Bakteriologie, \& Pettenkofer-institut, 2000; Wisner et al., 2012).

\subsubsection{SPI-2 T3SS and virulence}

SPI-2 T3SS secretes many effectors, however, most of their functions are still unknown. One important factor that the SCV acquires during the switch between SPI-1 to SPI-2 T3SSs 
systems is the V-ATPase that facilitates the acidification of the SCV. This acidification is important for the induction of Salmonella virulence and survival genes via the two-component regulatory systems PhoP/PhoQ and EnvZ/OmpR; as established by Hensel et al. in 2000, the inhibition of the V-ATPase reduces intracellular replication of Salmonella (Hensel et al., 2000; Kuhle \& Hensel, 2004). As the SCV goes through maturation it moves through the microtubules towards the Golgi apparatus, with many effectors contributing or directly blocking the delivery of the SCV to the lysosome during this process, preventing bacterial death (Kuhle \& Hensel, 2004). Other SPI-2 effectors are also able to contribute to the formation of Salmonella-induced filaments (Sifs) which are essential for maintaining the integrity of the SCV and also important in facilitating the virulence and dissemination of the pathogen to other host cells. 


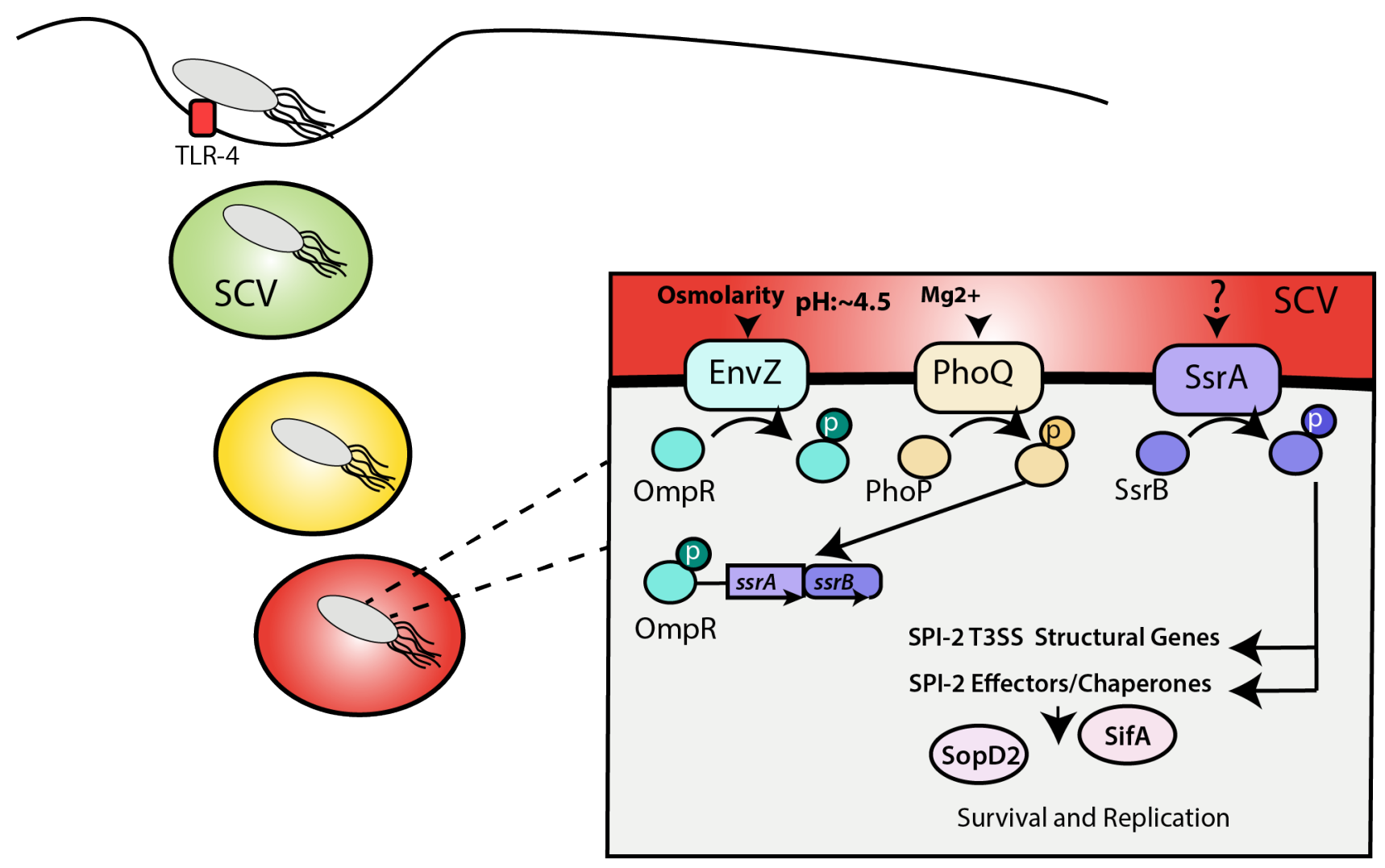

Figure 5. Salmonella SPI-2 virulence and regulation. A summary showing the regulation of SPI-2 T3SS by OmpR/EnvZ and PhoP/Q via ssrA/B. EnvZ senses changes inside the SCV activating OmpR, therefore inducing the expression of ssrA and ssrB, while PhoQ also sense environmental signals that activate PhoP, to induce expression of SsrB. SsrA senses an unknown signal, and it activate SsrB to induce expression of SPI-2 structural components and SPI-2 effectors that are needed for the survival and replication of Salmonella. 


\subsection{Pathogenic infections and TFEB-mediated clearance of infection}

TFEB has been linked to the up and down-regulation of lysosomal function and biogenesis in response to stressful conditions like, starvation, cellular and lysosomal stress, protein misfolding, mitochondrial dysfunction and pathogen infections (José A Martina \& Puertollano, 2016; Song et al., 2013). Once pathogens are detected by PRRs on the surface of host cells, they are either engulfed by phagocytosis or they invade through the use of specialized secretion systems, like the T3SS (D’Costa et al., 2015; Schroeder \& Hilbi, 2008). Immediately after being internalized, they are exposed to a number of different defense mechanisms within the phagosome and through its subsequent fusion with the lysosomes, leading to the activation of TFEB and upregulation of lysosomal activity and biogenesis (Dayam, Saric, Shilliday, \& Botelho, 2015; Torraca et al., 2014). Both, TFEB and HLH-30 ortholog in Caenorhabditis elegans (C. elegans), have shown to enhance the expression of host defense mechanisms and genes upon infection with different organisms like E.coli and S. aureus, suggesting TFEB is evolutionarily conserved and activated upon infection (Gray et al., 2016; Najibi et al., 2016). Gray et al, have shown the important role of TFEB activation in the induction of lysosomalbased degradation by enhancing expression of lysosomal genes, thereby decreasing the ability of microbes to survive within host cells (Gray et al., 2016). Ultimately, the goal of phagocytosis is to destroy the internalized cargo, on the contrary, intracellular pathogens have evolved mechanisms to counteract the host defenses and prevent degradation (Jorge E Galan, 2001; Torraca et al., 2014). These counter-strategies are often facilitated by virulence factors which are secreted directly into the host via T3SS used by pathogens like Salmonella typhimurium and Shigella flexneri (Picking et al., 2005; Rajashekar, Liebl, Chikkaballi, Liss, \& Hensel, 2014; Schroeder \& Hilbi, 2008). Pathogens can also induce significant reprogramming of the host 
cells' mechanisms by manipulating normal signaling pathways, which possibly includes TFEB activation. These mechanisms of manipulation used by pathogens to prevent degradation are poorly understood and more research needs to be done to understand how pathogens find a way to avoid degradation by phagocytic cells (Gray et al., 2016). As mentioned above, Salmonella is known for its clever ways of evading the defense mechanisms of phagocytic cells and being able to establish a successful infection inside the host. However, the exact mechanism of how this happens it's still not clear. This thesis will focus on understanding the different aspects of Salmonella infection and how they prevent TFEB activation most likely to avert lysosomal degradation.

\subsection{Rationale}

Microorganisms have evolved strategies to avoid degradation post phagocytosis. Some of these pathogens are able to arrest, divert or escape the various stages of phagosome maturation (Botelho \& Grinstein, 2011). Now that we understand the role of TFEB in the upscaling of lysosomes during phagocytosis of non-pathogenic bacteria and inert particles (Gray et al., 2016), we theorized that TFEB nuclear translocation will be reduced in RAW macrophages infected with pathogens that manipulate phagocytosis and/or phagosome maturation.

\subsection{Hypothesis}

We hypothesized that Salmonella actively blocks TFEB in order to enhance its own survival intracellularly.

To address this hypothesis, the following objectives were set: 
1. Determine if Salmonella typhimurium manipulates TFEB activation

2. Explore the potential causes of Salmonella manipulation

3. Investigate the role of TFEB in bacterial killing

\section{Experimental Procedures}

\subsection{Cell Culture}

Macrophage-like murine cell line RAW 264.7 were grown in Dulbecco's modified Eagle's medium (DMEM) supplemented with 10\% (v/v) fetal bovine serum (FBS) (Gibco) at $37^{\circ} \mathrm{C}$ and $5 \% \mathrm{CO}_{2}$. Cells are used up to 20 passages. Before plating, cells were washed with sterile phosphate-buffered saline (PBS), and released by scraping in $5 \mathrm{~mL}$ of DMEM media. Cells were seeded into 6-well or 12 -well plates at a confluency of $40 \%$ to be used the following day.

\subsection{Transfection}

Plasmid encoding-GFP fusion of TFEB was obtained from Dr. Ferguson's Lab (Yale University School of Medicine, CT) (Roczniak-Ferguson et al., 2012). Prior to transfection, cells were seeded at a $20-30 \%$ confluency, the following day, transfection was carried out using FuGene HD transfection reagents (Promega, WI) following manufacturer's instructions in 12well plates. Transfection mix was left on cells for $5 \mathrm{~h}$ followed by removal and addition of new growth media. Cells were used the following day.

\subsection{Bacterial strains}

Enterohemorrahgic Escherichia coli (EHEC), uropathogenic Escherichia coli (UPEC), wild-type Salmonella typhimurium strain (SL1344) and a strain deleted for phoP gene ( $\Delta$ phoP) were obtained from Dr. J McPhee’s laboratory at Ryerson University. Salmonella mutants 
( $\triangle$ sopD2, $\Delta$ sifA, $\Delta \operatorname{sirp}, \Delta \operatorname{sig} D(\operatorname{sop} B), \triangle \operatorname{ss} P H 2, \Delta \operatorname{sopA}, \triangle p i p B 2)$ were obtained from Dr. J. H Brumell at the Hospital for Sick Children (Toronto, ON). All strains were grown overnight in Luria-Bertani (LB) broth at $37^{\circ} \mathrm{C}$ with shaking, as described below.

\subsection{Bacterial growth and invasion assays}

To test the effect of growth phase of Salmonella on TFEB activation and survival, Salmonella were grown overnight to a stationary phase (which induces SPI-2 T3SS expression), or were sub-cultured the next day at 1:10 in fresh LB broth for $3.5 \mathrm{~h}$ to get late-log phase (SPI-1dependent invasion).

For phagocytosis and invasion assays, stationary phase bacteria were used unless otherwise indicated. The $\mathrm{OD}_{600}$ was measured to be between 0.6-0.8 and a 100:1 multiplicity of infection (MOI) of bacterium inoculum was calculated. This was then prepared by pelleting the bacteria at $12,000 \mathrm{xg}$ in a microcentrifuge for 8-10 min, and then re-suspended directly into new DMEM media on the treatment plate containing macrophages. Phagocytosis was synchronized through centrifugation of the culture plates at $400 \mathrm{xg}$ for $5 \mathrm{~min}$ at room temperature. Cells were allowed to phagocytose for $1 \mathrm{~h}$, unless stated otherwise. Cells were washed 3 times with $1 \mathrm{X}$ phosphate-buffered saline (PBS) and fixed with $4 \%(\mathrm{v} / \mathrm{v})$ paraformaldehyde (PFA) in PBS for

20 min, followed by quenching with $0.1 \mathrm{M}$ glycine in PBS for $20 \mathrm{~min}$. Cells were then processed for immunofluorescence or imaging as described below. Invasion treatments were done at $1 \mathrm{~h}, 4$ $\mathrm{h}$ and $6 \mathrm{~h}$, unless specified.

\subsection{Bacterial survival assay and gentamicin protection assays}

Prior to phagocytosis of unopsonized E. coli or WT S. typhimurium, RAW macrophages remained untreated, or were pre-activated with IgG-opsonized beads or rapamycin (1:1000) of a 
$10 \mathrm{mM}$ stock for $1 \mathrm{~h}$, followed by a $3 \mathrm{~h}$ chase. Treated or untreated macrophages were then infected with stationary-phase bacteria (E. coli and $S$. typhimurium) at a final $\mathrm{OD}_{600}=1.0 / \mathrm{mL}$ and uptake was synchronized through centrifugation at $400 \mathrm{xg}$ for $5 \mathrm{~min}$. At $1 \mathrm{~h}$ post-infection (pi), macrophages were washed 3X with PBS and replaced with DMEM media containing 50 $\mu \mathrm{g} / \mathrm{ml}$ gentamicin to kill extracellular bacteria for $30 \mathrm{~min}$. After, cells were washed $3 \mathrm{X}$ with PBS and either lysed immediately (uptake) with $200 \mu 1$ of 1\% triton X-100 for 5 min or the media was replaced with new DMEM supplemented with $10 \%$ FBS, containing low concentration of gentamicin $(12 \mu \mathrm{g} / \mathrm{ml})$, and incubated for $3 \mathrm{~h}$ at $37^{\circ} \mathrm{C}$ to allow time for phagosome maturation and bacteria killing. Prior to lysing, cells were washed multiple times with PBS and replaced with DMEM media containing $50 \mu \mathrm{g} / \mathrm{ml}$ gentamicin to kill extracellular bacteria for $30 \mathrm{~min}$. They were then washed $3 X$ with PBS and lysed with $200 \mu 1$ of $1 \%$ triton X-100 for 5 min and scraped to release bacteria. Cell lysates were re-suspended in $800 \mu 1$ of PBS and subjected to serial dilutions in LB broth, followed by plating of $10 \mu \mathrm{l}$ in freshly made LB plates and incubated overnight at $37^{\circ} \mathrm{C}$. Colony numbers were counted and recorded to determine $\mathrm{CFU} / \mathrm{mL}$.

\subsection{Immunofluorescence and fluorescence microscopy}

To visualize external bacteria in TFEB-GFP transfected cells, immunostaining was conducted by briefly washing cells $3 \mathrm{X}$ with $0.5 \%$ Bovine Serum Albumin (BSA). Primary and secondary antibodies were diluted $1: 500$ in $0.5 \%$ BSA from a stock concentraction of $0.5 \mathrm{mg} / \mathrm{ml}$. Cells were incubated with primary antibody against the bacteria (DH5 $\alpha$ - rabbit anti-Escherichia coli (BioRad, ON), Salmonella typhimurium - rabbit anti-Salmonella O antiserum group B (Fisher Scientific, ON) for 30 min before washing $3 \mathrm{X}$ with $0.5 \%$ BSA. Cells were incubated for 30 min with secondary antibody donkey anti-rabbit antibodies conjugated to Dylight $355 \mathrm{~nm}$ 
(Bethyl Laboratories, TX) before permeabilization to detect external bacteria. To visualize internal bacteria, cells were permeabilized with $1 \%$ triton X-100, followed by incubation with the same primary antibody against the bacteria but now using a different secondary antibody, donkey anti-rabbit Dylight 550nm (Bethyl Laboratories, TX). Cells were washed 3X with $0.5 \%$ BSA and mounted onto glass slides with fluorescent mounting media (DAKO) for imaging.

For endogenous TFEB localization cells were fixed with $4 \%$ PFA (v/v) at room temperature for $20 \mathrm{~min}$ and $0.1 \mathrm{M}$ glycine in PBS for $20 \mathrm{~min}$, before being washed $3 \mathrm{X}$ with $0.5 \%$ BSA and permeabilized with $0.1 \%$ triton for $10 \mathrm{~min}$. Cells were blocked for $30 \mathrm{~min}$ with $0.5 \%$ BSA, before incubating them with rabbit anti-TFEB antibodies (Bethyl Laboratories, TX) was diluted 1:250 in $0.5 \%$ BSA of a $1 \mathrm{mg} / \mathrm{ml}$ antibody stock. Coverslips were flipped onto $50 \mu 1$ of the primary antibody mixture for $30 \mathrm{~min}$. They were then flipped back into their corresponding wells and washed $3 \mathrm{X}$ with $0.5 \%$ BSA, followed by an incubation with Dylight 488 -conjugated donkey anti-rabbit antibodies (Bethyl Laboratories, TX) at a dilution of 1:500 for $30 \mathrm{~min}$. Cells were washed $2 \mathrm{X}$ with $0.5 \% \mathrm{BSA}$, and were incubated for $5 \mathrm{~min}$ with $0.4 \mu \mathrm{g} / \mathrm{ml}$ dilution of DAPI (4',6-diamidino-2-phenylindole), and then washed $2 \mathrm{X}$ with $0.5 \% \mathrm{BSA}$ before mounting onto glass slides with fluorescent mounting media (DAKO) for imaging.

Fluorescently labelled samples were imaged using $60 \mathrm{X}$ oil immersion objective in an Olympus IX83 Inverted Microscope linked to a Hamamatsu ORCA-Flash 4.0 digital camera (Olympus, ON). Most images are shown as epifluorescence, non-deconvolved images, while others were subjected to deconvolution using CellSens Dimension module (Olympus, ON) with the advanced maximum likelihood estimation algorithm (ADVMLE). Deconvolution is an 
image processing technique that is being largely used for improving the contrast and resolution of digital images captured in a microscope.

\subsection{Image analyses}

To quantify nuclear to cytosol TFEB intensity, images were acquired either through single slice acquisition or Z stacks. Z-stack images were deconvolved to reduce out of focus light and improve contrast and resolution, while single slice images remained untouched. Images were analyzed using ImageJ (NIH, MD). For nuclear to cytosolic TFEB ratio, regions of interest where drawn around the nucleus and in the cytosol and the intensities within these regions were then measured. After background subtraction, the ratio of nuclear to cytosol fluorescence was calculated.

\subsection{Statistical analyses}

All experiments were repeated independently at least 3 times. In some cases, due to the variation in the plating of RAW cells, the data shows normalized mean values against the corresponding control. All data were subjected to analysis of variance (ANOVA) followed by Tukey's post-hoc test. A p-value of $<0.05$ was considered significant. Data are presented as mean \pm standard error of the mean (SEM), unless stated otherwise. 


\section{Results}

\subsection{Phagocytic uptake of non-opsonic pathogenic E.coli activates TFEB nuclear translocation}

In order to understand the importance of TFEB in the killing of intracellular pathogens, we first assessed how TFEB responded to phagocytosis of non-pathogenic (DH5 $\alpha$ ) and pathogenic E.coli (UPEC and EHEC), both of which are unable to prevent lysosomal degradation in murine macrophages (Horvath et al., 2011; Poirier et al., 2008) . Using the macrophage cell line RAW 264.7, which has been widely used in the study of phagocytosis and lysosomal degradation, we examined TFEB translocation in macrophages expressing TFEB-GFP after phagocytosis of nonopsonized live UPEC, EHEC and DH5 $\alpha$ (D’Costa et al., 2015; Horvath et al., 2011; Kuhle \& Hensel, 2004; Pastore et al., 2016; Wisner et al., 2012; Zhao et al., 2015). In order to ensure results were due to the uptake of the bacteria and not a simple ligand-receptor interaction, we fluorescently labelled external and internal bacteria. TFEB-GFP was predominantly cytosolic in resting macrophages, whereas cells that engulfed EHEC, UPEC or non-pathogenic E.coli displayed TFEB-GFP in the nucleus (Gray et al., 2016) (Fig. 6A). To quantitatively assess TFEB nuclear translocation, we measured fluorescence intensity ratio of nuclear to cytosolic TFEB by manually drawing regions of interest within the nucleus and cytosol (Fig. 6B). Our data show that phagocytosis of DH5 $\alpha$, UPEC and EHEC cause nuclear translocation of TFEB. 

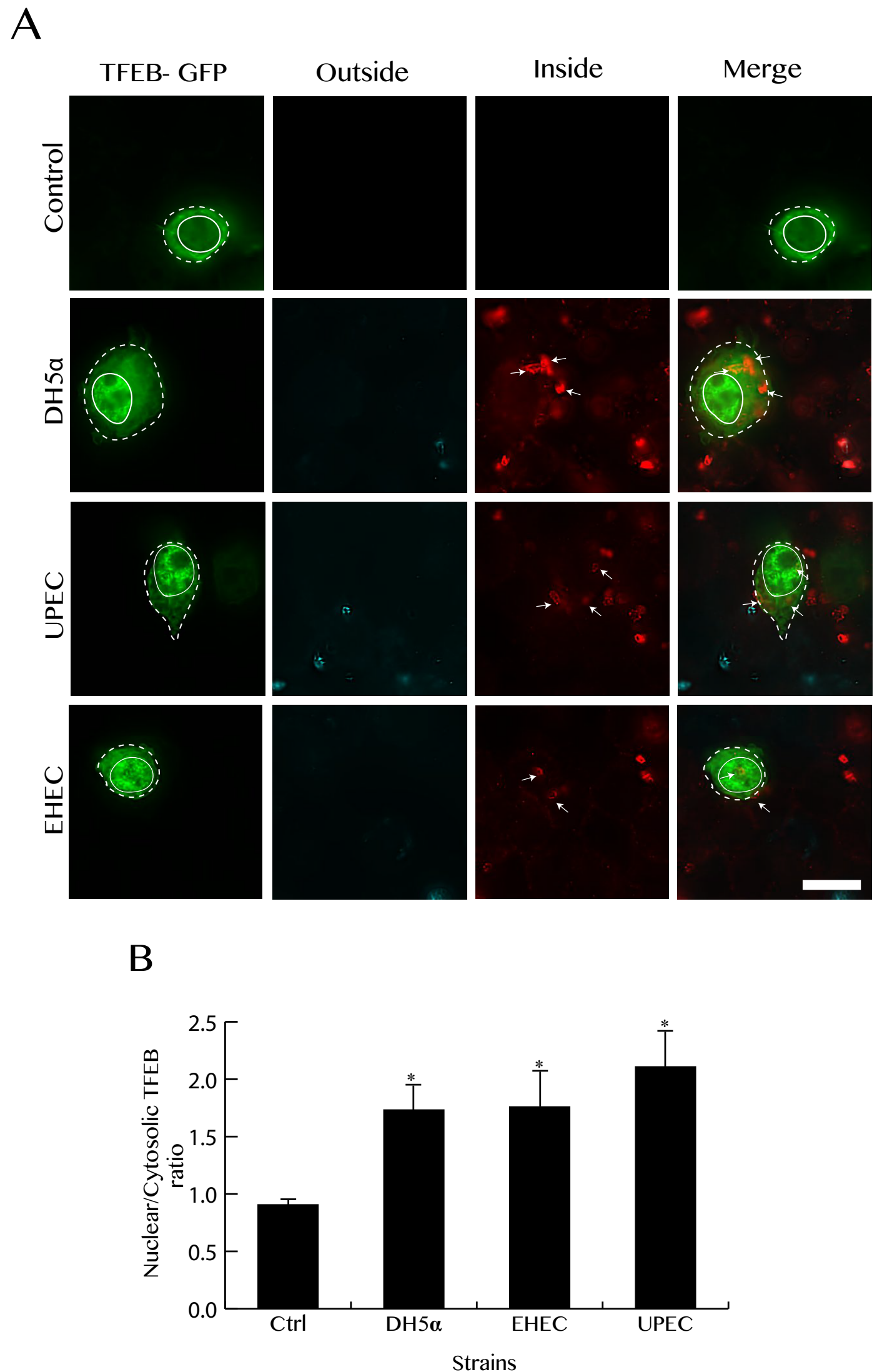
Figure 6. Phagocytosis of non-opsonized pathogenic and non-pathogenic E.coli causes TFEB nuclear translocation in TFEB-GFP transfected cells. RAW 264.7 macrophages expressing TFEB-GFP were infected for $1 \mathrm{~h}$ with non-opsonic live pathogenic (UPEC, EHEC) and non-pathogenic E.coli (DH5 $\alpha)$. A) External bacteria were identified by labelling with rabbitanti-E.coli antibodies before and after permeabilizaiton (red and pseudo-cyan), while internal bacteria were only labelled with rabbit-anti E.coli antibody after permeabilization (red). Arrows indicate internalized bacteria. B) The nuclear to cytosolic TFEB-GFP ratio was quantified for all the strains. Data is based on three independent experiments with approximately 100 cells counted per condition per experiment. Data were statistically analyzed with ANOVA followed by Tukey's HSD post-hoc test relative to resting cells; * indicates statistical significance at $\mathrm{p}<0.05$. Scale bar represents $10 \mu \mathrm{m}$. 


\subsection{Salmonella typhimurium actively manipulates TFEB cellular localization.}

In contrast to E.coli, Salmonella hijacks and exploits the host intracellular trafficking and defense systems to evade phagocytic destruction (Ashida, Mimuro, \& Sasakawa, 2015). In order to understand how this evasion affects TFEB activation, we infected RAW 264.7 macrophages with stationary phase WT live Salmonella, SL1344, for $1 \mathrm{~h}$ and stained for internal and external bacteria as previously mentioned in section 3.1. It was observed that after phagocytosis of viable WT Salmonella TFEB remained cytosolic, similar to resting cells (Fig. 7A). Considering that phagocytosis of live, wild-type Salmonella did not trigger nuclear translocation of TFEB, we decided to investigate if this was an active repression by Salmonella or if the receptor-ligand interaction needed to signal host defense mechanisms was absent, preventing TFEB activation. To test this, we looked at live stationary phase Salmonella, as well as heat-killed (non-viable) Salmonella that should still possess the same ligands as live-Salmonella (Bosisio et al., 2002; Najibi et al., 2016; Newman et al., 2013). As expected, phagocytosis of non-viable Salmonella was unable to prevent TFEB activation compared to its live counterpart (Fig. 7A). TFEB-GFP nuclear vs cytosolic intensity was measured for all conditions (Fig. 7B). Taken together, these results indicate that Salmonella is preventing TFEB activation through an active process. 

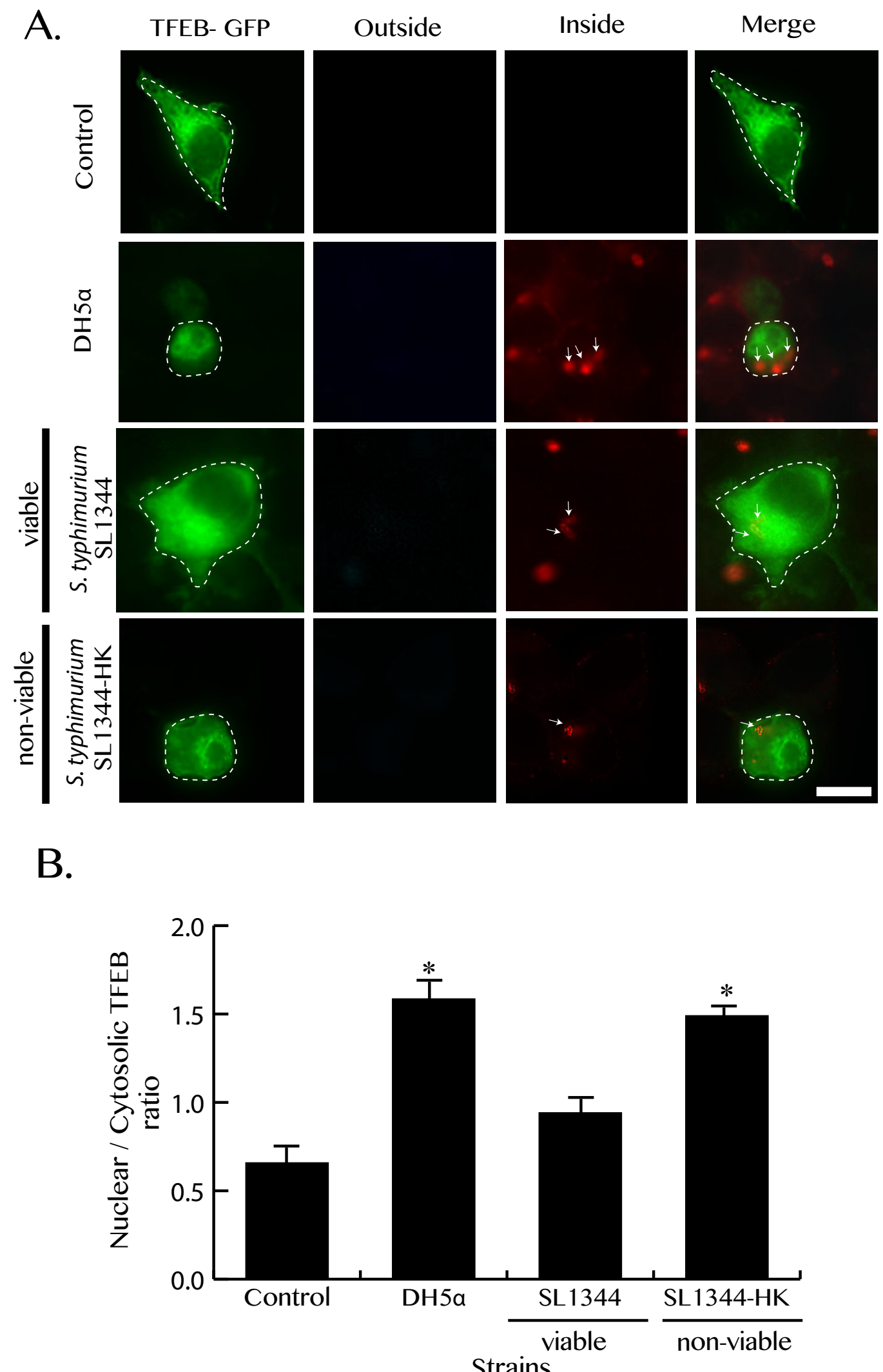
Figure 7. Salmonella typhimurium actively prevents TFEB activation. RAW 264.7

macrophages expressing TFEB-GFP were infected for $1 \mathrm{~h}$ with E.coli and viable and non-viable (heat-killed at $90^{\circ} \mathrm{C}$ ) WT Salmonella strains (SL1344). A) Internal bacteria were labelled with rabbit-anti E.coli antibody (red) only, while external bacteria were labelled with rabbit-antiE.coli antibodies (red and pseudo-cyan) prior to permeabilization. Arrows indicate internalized bacteria. B) Nuclear to cytosolic TFEB-GFP intensity ratio was quantified for all strains. Data is based on three independent experiments with approximately 50 cells counted per condition per experiment. Data were statistically analyzed with ANOVA followed by Tukey’s HSD post-hoc test relative to resting cells; $*$ indicates statistical significance at $\mathrm{p}<0.05$ relative to the control. Scale bar represents $10 \mu \mathrm{m}$. 


\subsection{Salmonella manipulates TFEB in a time-dependent manner}

Salmonella virulence is known to be time-dependent due to the tightly controlled expression of their T3SS needed at different times of infection (Wisner et al., 2012). Having established that Salmonella blocks TFEB activation at an early time post-infection (p.i), we aimed to determine if the above observations were consistent throughout the infection process. To do so, we infected RAW macrophages with viable E. coli and WT Salmonella (SL1344) for 1, 4, and $6 \mathrm{~h}$. We also fixed and stained cells for endogenous TFEB instead of transfection to better reflect the physiological response of TFEB. As previously seen, WT Salmonella represses TFEB at an early stage of infection, nonetheless, to our surprise TFEB began to accumulate in the nucleus in macrophages infected with Salmonella after 4 and $6 \mathrm{~h}$ of infection (Fig. 8). These results suggest that at later periods of infection Salmonella might lose the ability to repress TFEB or could potentially induce its activation. 


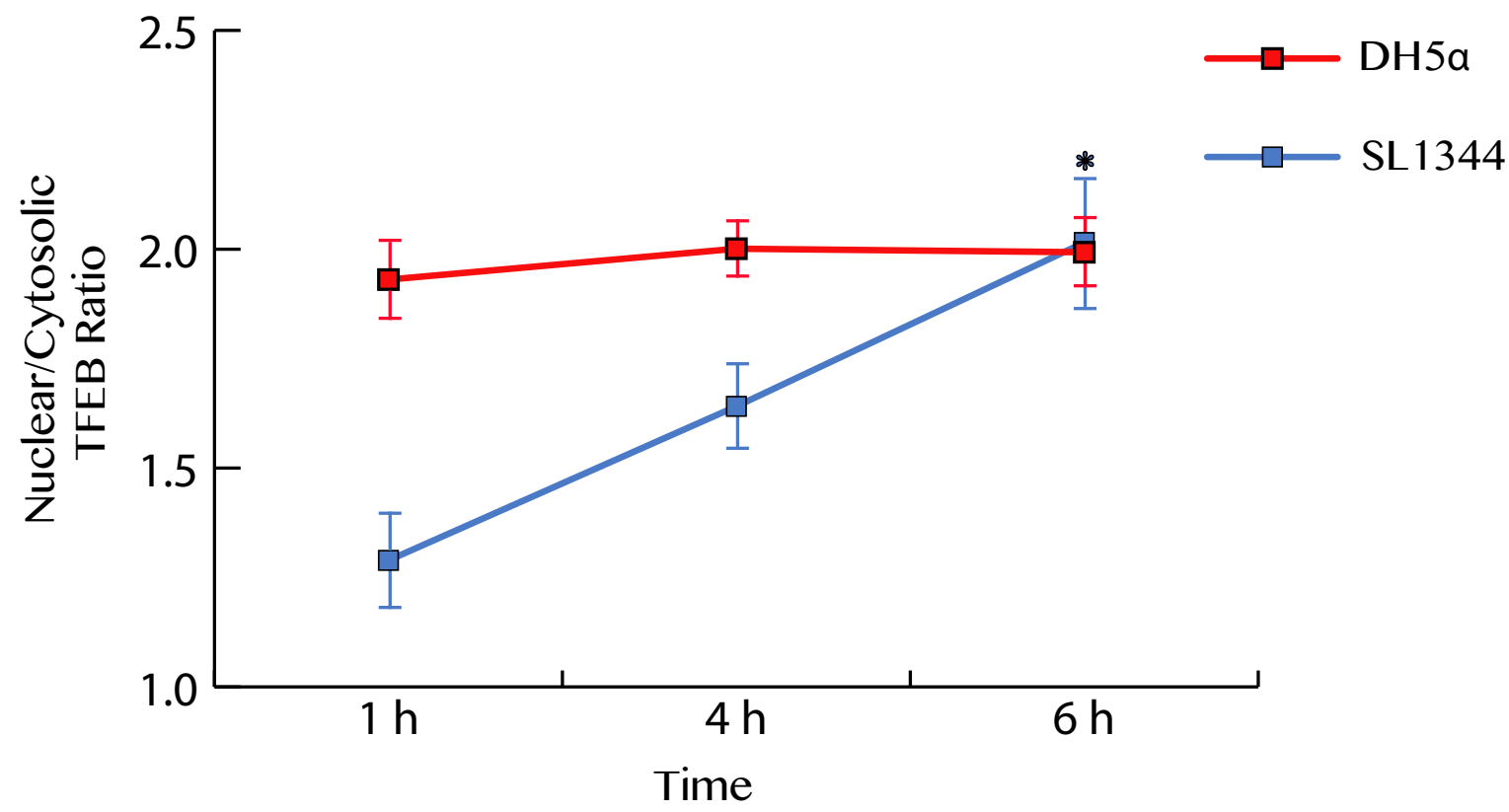

Figure 8. TFEB nuclear translocation is greater at later time-points of Salmonella infection. RAW 264.7 macrophages were infected with E.coli and WT Salmonella (SL1344) for various time-points $(1,4,6 \mathrm{~h})$. Data is normalized to the control, nuclear to cytosolic TFEB intensity was quantified. Data is based on three independent experiments with approximately 50 cells counted per condition per experiment. Data were statistically analyzed with ANOVA followed by Tukey's HSD post-hoc test relative to resting cells; * indicates statistical significance at $\mathrm{p}<0.05$ against the $1 \mathrm{~h}$ condition. 


\subsection{Growth conditions affect Salmonella's way of interacting with the host.}

The above data suggest that some aspect of Salmonella pathogenesis is preventing TFEB activation in a time-dependent manner. We next examined how the different growth phases of Salmonella through infection might influence this variation. It is known that Salmonella interacts with host cells differently depending on its growth phases; for example, late-log and stationary Salmonella is able to induce the expression of SPI-1 or SPI-2 T3SSs, respectively (Brumell et al., 2003)'(Miao, Li, Zhang, Xu, \& Abraham, 2015; Sridhar \& Steele-mortimer, 2016). SPI-1 T3SS expression is required for invasion of non-phagocytic cells, whereas SPI-2 T3SS expression is mainly needed for survival and replication within macrophages (Brumell et al., 2003)'(Sridhar \& Steele-mortimer, 2016)'(Lai, Xu, Chen, \& Ren, 2015) . To test this, nonpathogenic E.coli and WT Salmonella were grown overnight to a stationary phase to induce SPI$2 \mathrm{~T} 3 \mathrm{SS}$ expression. In comparison, we sub-cultured some overnight culture for $3.5 \mathrm{~h}$ prior to infection to obtain late-log growth and express SPI-1 T3SS. As seen before, phagocytosis of Salmonella grown to stationary phase repressed TFEB in the first hour p.i, and at later time points TFEB started to slowly shuttle into the nucleus. In contrast to the stationary phase bacteria, phagocytosis of late-log (SPI-1 induced) bacteria, had a higher nuclear TFEB intensity at early times p.i, but TFEB nuclear intensity declined at later stages of infection (Fig. 9). Collectively, these results demonstrate that Salmonella growth conditions can differentially modulate TFEB. 


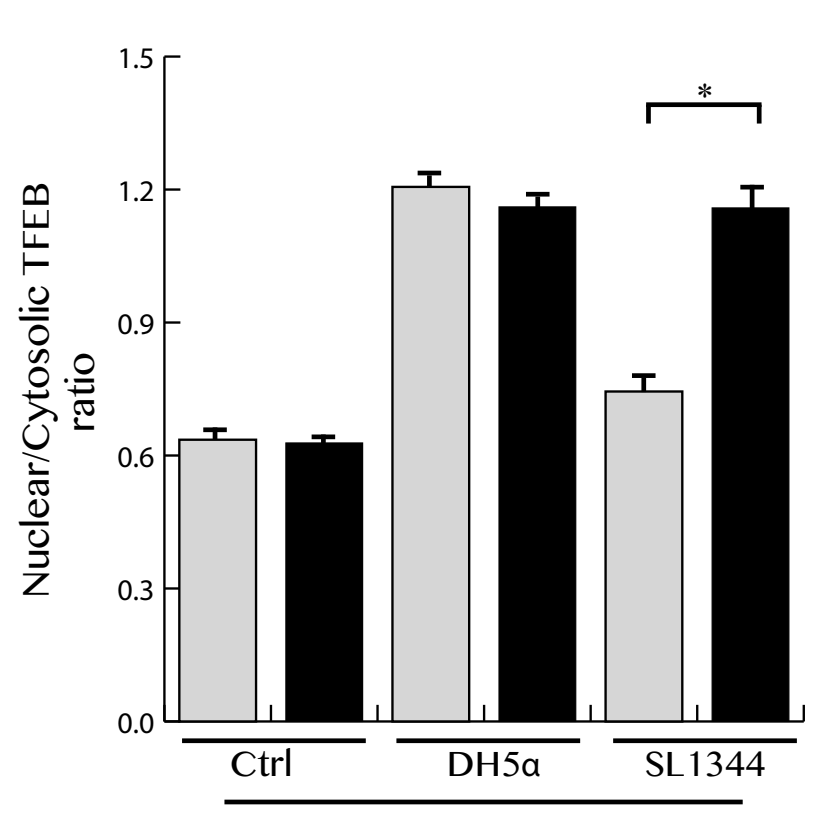

$1 \mathrm{~h}$
Stationary (SPI-2)

Late-log (SPI-1)

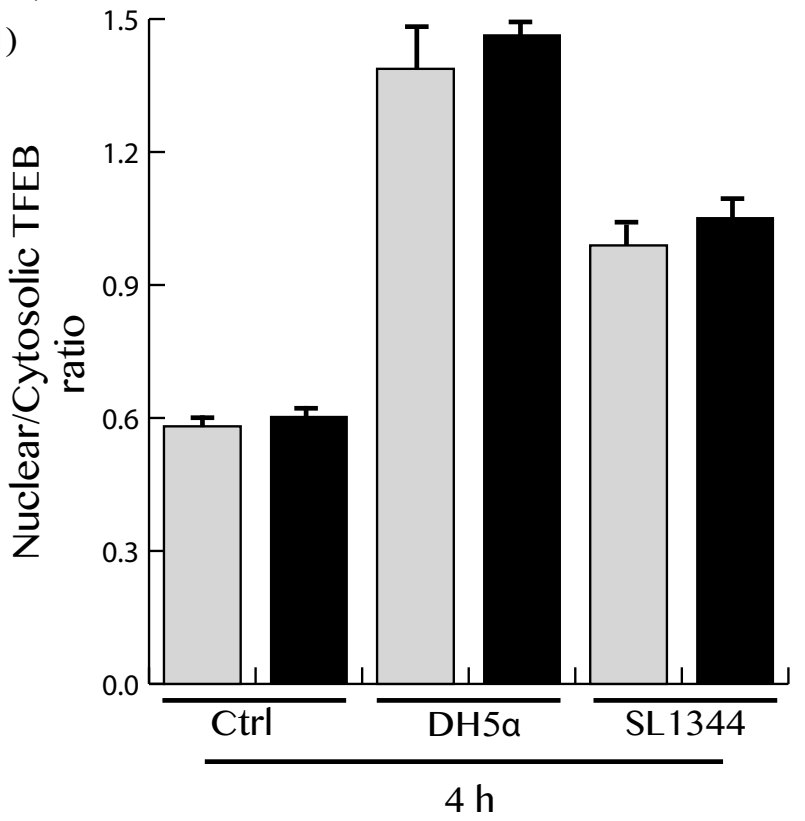

Figure 9. Salmonella growth conditions affect TFEB subcellular location. RAW 264.7

macrophages were infected with stationary (Salmonella-SPI-2 induction) and late-log (Salmonella-SPI-1 induction) E.coli and WT Salmonella (SL1344). Nuclear/cytosolic TFEB ratio was quantified for 1 and $4 \mathrm{~h}$ p.i. Data is based on five independent experiments with approximately 70 cells counted per condition per experiment. Data was statistically analyzed with ANOVA. * Significant ( $\mathrm{p}>0.05$ ) between the growth phases, followed by Tukey's HSD post-hoc test. 


\subsection{SPI-2 effector defects in Salmonella promote TFEB nuclear translocation}

Considering the importance of growth conditions in the behaviour and virulence of Salmonella, we decided to further examine how stationary-grown Salmonella might be repressing TFEB at an early period p.i. To do this, we employed mutants of the SPI-2 regulator and SPI-2 effectors required for Salmonella survival, replication and virulence of the bacterium (Gray et al., 2016; Settembre, C,, Di malta C., Polito VA, Garcia Arencibia, Vetrini F, Erding S, 2012)'(Brumell, Rosenberger, Gotto, Marcus, \& Finlay, 2001; Cirillo, Valdivia, Monack, \& Falkow, 1998; D’Costa et al., 2015). We obtained SL1344 isogenic mutants from Dr. John Brumell at Sick Kids Hospital in Toronto and Dr. J. McPhee at Ryerson University. We performed the same experiment as described in section 3.2 with the isogenic mutants. Some, but not all mutants had the inability to prevent TFEB translocation, compared to the WT Salmonella (SL1344) strain in the first hour p.i. (Fig. 10A). As we can see in Figure 10, the Salmonella mutants with most remarkable TFEB nuclear translocation were $\Delta p h o P, \Delta s i f A$ and $\Delta s o p D 2$. SopD2 and SifA are SPI-2 effectors, while PhoP is a response regulator that regulates the transition from SPI-1 to SPI-2 T3SS and it's also involved in the expression of SPI-2 effectors and SPI-2 structural components (Brumell et al., 2003, 2001; D’Costa et al., 2015; Pegues, Hantman, Behlau, \& Miller, 1995; Will, Bale, Reid, Libby, \& Fang, 2014; Wisner et al., 2012). The rest of the mutants failed to activate TFEB and behaved similarly to the WT strain and to resting cells (not shown in Fig. 10A). TFEB nuclear to cytosolic intensity ratio was measured for all strains as previously described (Fig. 10B). In order to ensure results obtained were not due to stress imposed on the cells during transfection, experiments were repeated using nontransfected cells labelled for endogenous TFEB with anti-TFEB antibodies (Fig. 11A). TFEBGFP nuclear to cytosolic intensity was measured (Fig. 11B). Overall, we have identified a few 
Salmonella SPI-2 mutants that are potentially necessary for the virulence of Salmonella and its survival. 

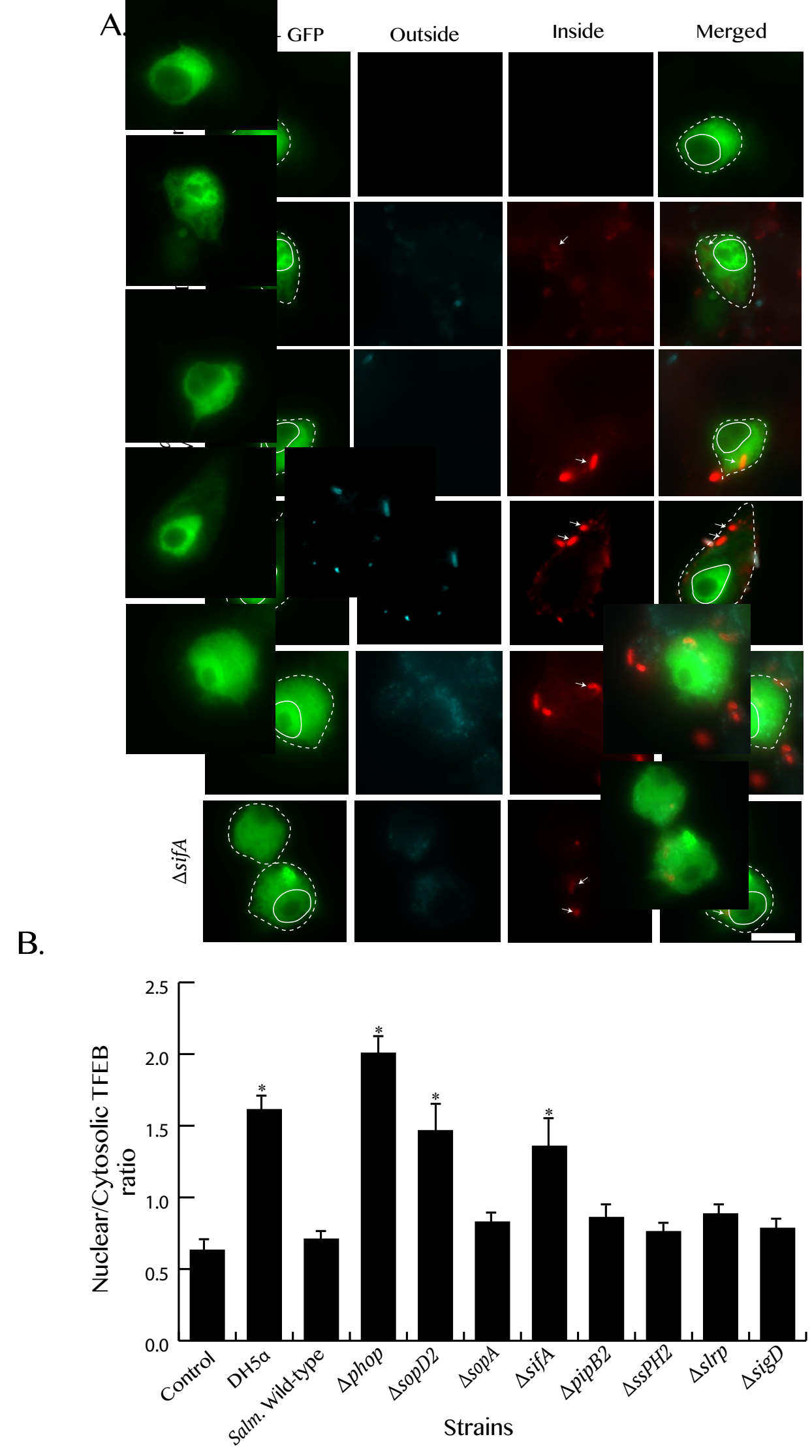
Figure 10. Identification of Salmonella mutants that lose the ability to block TFEB-GFP nuclear translocation in transfected RAW 264.7 macrophages. TFEB-GFP transfected RAW macrophages were allowed to phagocytose viable E.coli (DH5 $\alpha$ ), WT S. typhimurium (SL1344) and Salmonella strains lacking a variety of SPI-2 components and effectors. A) Internal bacteria were labelled with mCherry (red) only, while external bacteria were labelled with both mCherry and rabbit-anti-E.coli or rabbit-anti-Salmonella antibodies (pseudo-cyan) prior to permeabilization. This figure is just a graphical representation of the mutants that activate TFEB. Arrows indicated internalized bacteria. Scale bar represents $10 \mu \mathrm{m}$. B) Quantification of nuclear/cytosolic TFEB ratio for all mutants. Data is based on three independent experiments with approximately 50 cells counted per condition per experiment. Data was statistically analyzed with ANOVA, followed by Tukey's HSD post-hoc test. * Significant $(\mathrm{p}>0.05)$ relative to WT Salmonella. 
A.

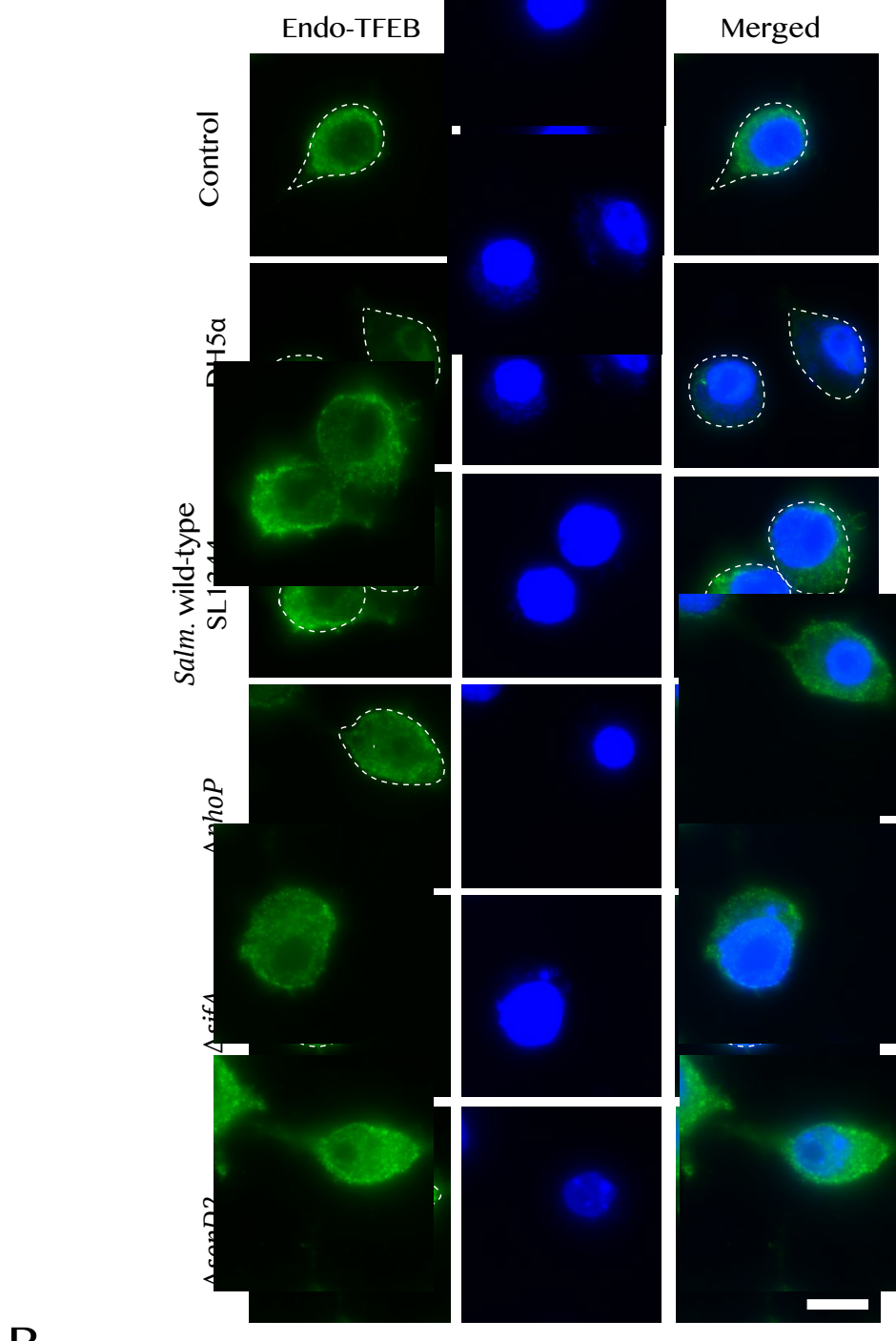

B.

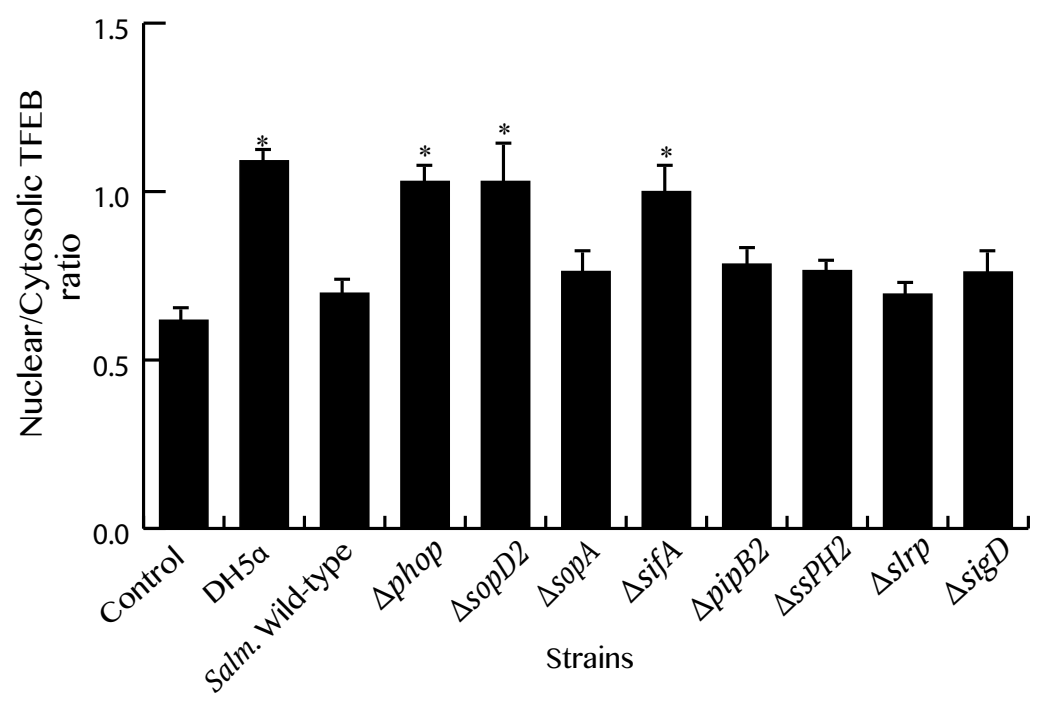


Figure 11. Identification of Salmonella mutants that fail to block TFEB in non-transfected

cells. RAW macrophages were allowed to phagocytose viable E.coli (DH5 $\alpha)$, WT $S$.

typhimurium (SL1344) and Salmonella strains lacking SPI-2 component and effectors, followed by fluorescent labelling of endogenous TFEB using rabbit-anti- TFEB antibodies, followed by a DAPI wash to identify the nucleus. Scale bar represents $10 \mu \mathrm{m}$. B) Quantification of nuclear/cytosolic TFEB ratio for all mutants. Data is based on three independent experiments with approximately 50 cells counted per condition per experiment. Data was statistically analyzed with ANOVA, followed by Tukey's HSD post-hoc test. * Significant $(\mathrm{p}>0.05)$ relative to WT Salmonella. 


\subsection{TFEB is required for lysosomal-based degradation of bacteria}

Previous research from our lab has shown that TFEB activation and its subsequent nuclear translocation is important for lysosomal-based degradation of non-opsonic E.coli (Gray et al., 2016). In this context, it will be interesting to speculate that TFEB repression in Salmonella infected cells will do the opposite as described above. To do so, we examined survival of intracellular Salmonella within macrophages by doing a gentamicin protection assay (GPA), an assay used to study intracellular pathogens ex-vivo (Wu et al., 2014). In this assay, extracellular pathogens are unable to avoid death by antibiotics like gentamicin while intracellular bacteria are protected from antibiotics that cannot penetrate the eukaryotic cell. Thus, GPA can be used to measure internalization and survival of intracellular pathogens (Mandell, 1973; Sridhar \& Steele-mortimer, 2016; van der Velden et al., 2000; Wu et al., 2014). For this experiment, RAW 264.7 WT and TFEB-/- (TFEB knock-out) RAW macrophages were used in order to understand the importance of TFEB in the killing of bacteria. The TFEB-/- cells were obtained from Dr. R. Puertollano's lab at the National Institute of Health (NIH) and they were created using the CRISPR/Cas9 (Clustered regularly interspaced short palindromic repeats/Caspase 9) genome editing tool (Pastore et al., 2016). CRISPR/Cas9 is a technique that allows sequence-specific editing in many organisms, when paired with Cas9 enzyme. CRISPR can cleave genomic DNA in a site specific manner with the help of a guide RNA (gRNA), therefore knocking out gene expression (Paquet et al., 2016; Pastore et al., 2016). The GPA was carried out as described in section 2.5. As expected, E.coli (DH5 $\alpha)$ was killed by WT RAW macrophages, whereas WT Salmonella survived and replicated within these same cells. In contrast to the WT RAW macrophages, both the DH5 $\alpha$ and the WT Salmonella survived better 
and replicated inside the TFEB-KO macrophages (Fig 12). These results are indicative of the importance of TFEB in stalling and clearing bacteria after phagocytosis. 


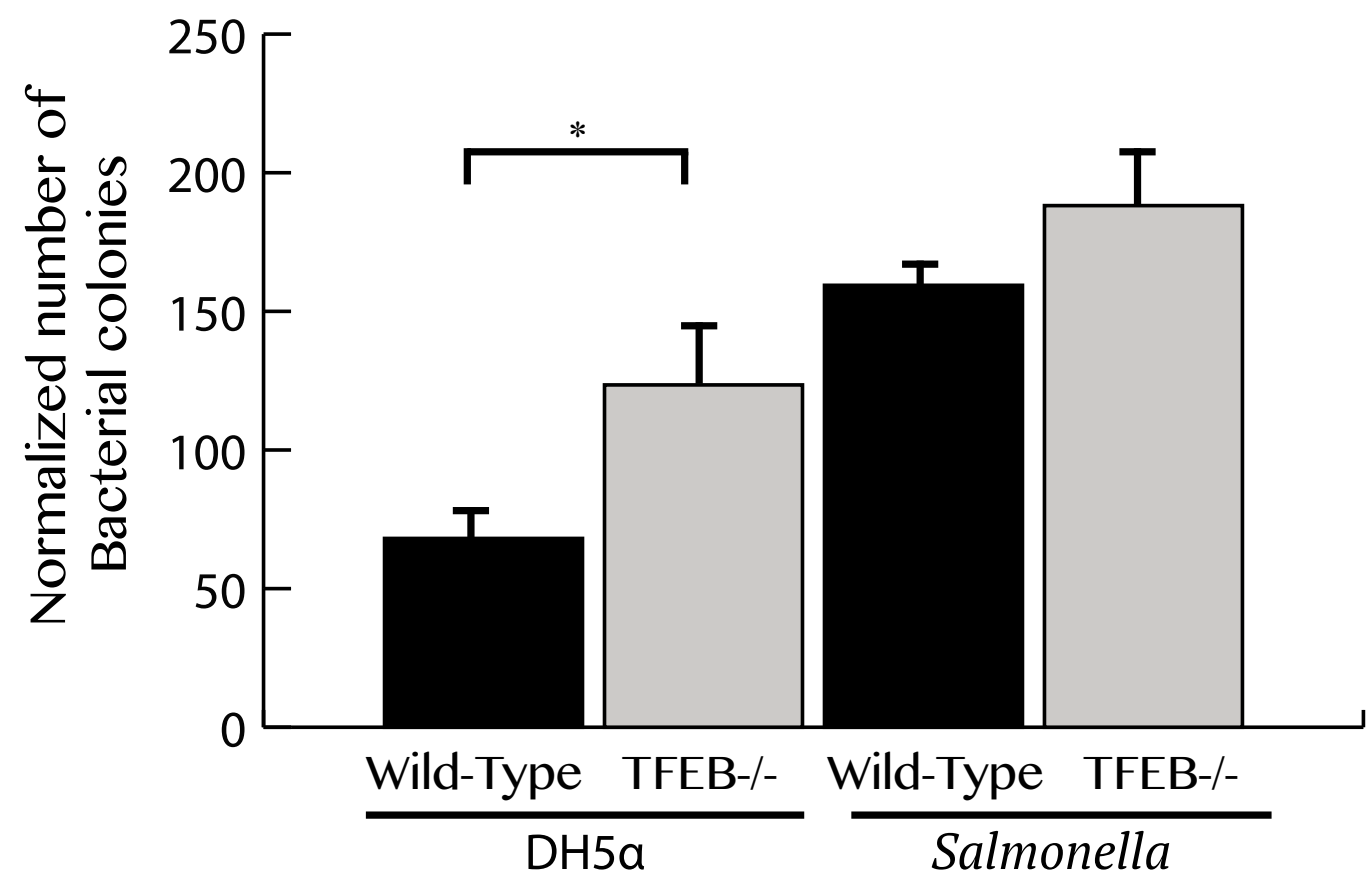

Figure 12. TFEB is necessary for bacterial clearance. Wild-type RAW and TFEB-/macrophages were allowed to phagocytose live E. coli and WT S. typhimurium. Internalized bacteria were recovered after $1 \mathrm{~h}$ infection (Uptake), just after gentamicin treatment, and at $4 \mathrm{~h}$ (Survival) after a second round of gentamicin treatment. Data is normalized to uptake and shows bacteria survival after $4 \mathrm{~h}$ phagocytosis. Data is based on six independent experiments and it was statistically analyzed with ANOVA, followed by Tukey's HSD post-hoc test. * Significant $(\mathrm{p}>0.05)$ relative to WT RAW macrophages. 


\subsection{TFEB pre-activation makes macrophages better killers}

Our previous observations show that TFEB activation is necessary for bacterial killing. To further complement these results, we decided to test survival in pre-activated macrophages, as formerly done by Gray et al., 2016, followed by a GPA. Pre-activation of TFEB within macrophages was done by using two different methods: pre-activation with phagocytosis of IgGopsonized beads (OB) and by inhibition of mTORC1 with Rapamycin. OB is recognized by the Fc $\gamma R$ followed by engulfment and degradation, leading to enhanced proteolytic and degradative activity of macrophages and an increase in TFEB nuclear translocation (Gray et al., 2016). In comparison, Rapamycin is an inhibitor that acts through an allosteric mechanism that acutely blocks some of mTORC1 activities, preventing TFEB phosphorylation and promoting TFEB nuclear localization (Palmieri, Pal, Nelvagal, et al., 2017; Thoreen \& Sabatini, 2009). Similar to our results in section 3.6, non-stimulated WT RAW macrophages have the ability to kill E.coli, but not WT Salmonella (Fig. 12). In comparison, macrophages lacking TFEB had reduced ability to kill either bacteria (Fig. 12). When pre-activating TFEB in WT RAW macrophages with OB, we saw that E.coli was killed more effectively and the ability of Salmonella to survive and replicate within the macrophages decreased (Fig. 13). Similar results were seen for the Rapamycin treated WT RAW macrophages. However, for both activated TFEB-/- cells, we did not see a change in the killing capacity of cells, demonstrating that TFEB enhances proteolytic activity and increases killing. These results further suggest a potential and promising role of TFEB activation in the clearance of bacterial infections. 

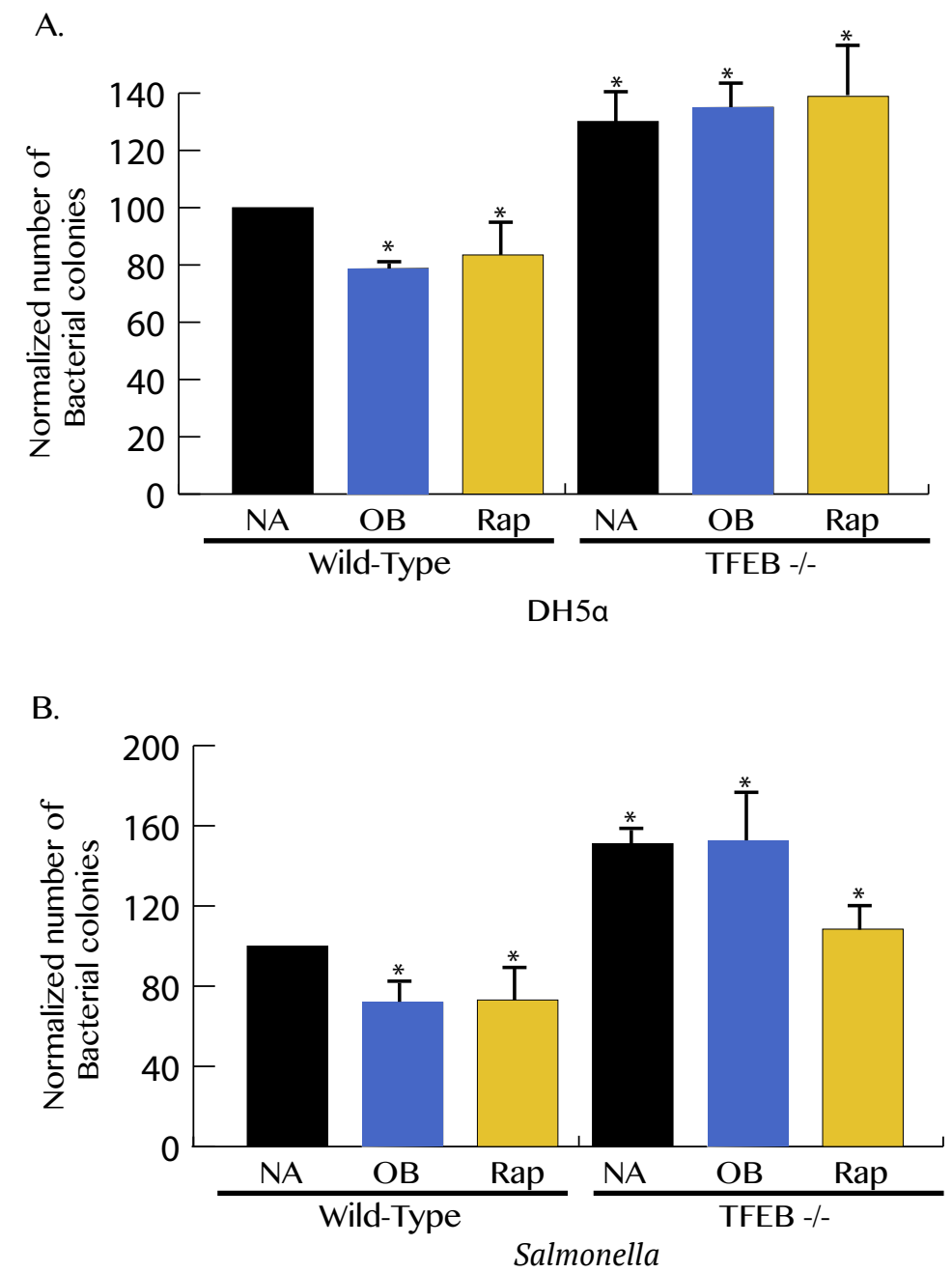

Figure 13. TFEB pre-activation increases the macrophage's ability to clear infections.

Wild-type RAW and TFEB -/- macrophages remained untreated or were either pre-activated with IgG- opsonized-beads (OB) or rapamycin for $1 \mathrm{~h}$ pulse, and $3 \mathrm{~h}$ chase, followed by phagocytosis of live E. coli (A) or Wild-type S. typhimurium (SL1344) (B). Internalized bacteria were recovered after $1 \mathrm{~h}$ infection (Uptake), just after gentamicin treatment, and $4 \mathrm{~h}$ (Survival) after a second gentamicin treatment. Data is normalized to uptake and non-activated WT treatment, showing only survival after $4 \mathrm{~h}$ phagocytosis. Data is based on four independent experiments. Data was statistically analyzed with ANOVA, followed by Tukey's HSD post-hoc test. * Significant $(\mathrm{p}>0.05)$ relative to the non-activated treatment. 


\section{Discussion}

\subsection{Summary of findings}

The ability of Salmonella to infect and replicate within macrophages can be used as a model for studying the immune response against pathogens. In this study, we wanted to get further insight into the mechanisms that Salmonella typhimurium uses to prevent degradation and also to evaluate the importance of TFEB in the enhancement of lysosomal-based degradation of Salmonella. In summary, we found that Salmonella improves its survival rate by actively blocking TFEB activation and nuclear translocation. We showed that this TFEB blockage is time-dependent and also dependent on the induction of the different SPI T3SSs during the different growth phases of Salmonella. Finally, we provide evidence that TFEB pre-activation may improve the ability of macrophages to clear infections.

\subsection{Pathogenic and non-pathogenic E. coli activate TFEB}

TFEB has emerged as an important regulator of many cellular processes, but more importantly, has been studied for its role as a master regulator of lysosomal-production and its part in immunity (Gray et al., 2016; Pastore et al., 2016). Our lab has previously shown that TFEB activation through Fc $\gamma \mathrm{R}$-mediated phagocytosis increases lysosomal-based degradation and bacterial killing by boosting the expression of lysosomal proteins (Gray et al., 2016). We wanted to examine the role of TFEB activation through different receptor-ligand interactions. For this, we used UPEC and EHEC. Very few studies have focused on the interaction of EHEC and murine macrophages. EHEC is a gram-negative pathogenic E.coli that is recognized by TLR-4 through its LPS molecule and once internalized by phagocytes, is able to produce high levels of Shiga-toxins (Stx) inside the phagosomes. The bacteria is delivered to the lysosomes 
for degradation and Stxs get released from the cell most likely through exocytosis (Poirier et al., 2008; Shimada, Ishikawa, Tosaka-Shimada, \& Atsumi, 1999) This explanation correlates with our findings suggesting that EHEC is rapidly killed by RAW macrophages, thereby increasing the degradative activity of the lysosomes which is in part due to TFEB activation (Fig. 6). UPEC on the other hand, has evolved morphological plasticity that gives them an advantage against phagocytic destruction (Olson \& Hunstad, 2016). In this case, bacillary UPEC gets phagocytosed and killed more effectively than filamentous UPEC, which seem to be resistant to phagocytosis. This morphological transition usually occurs at approximately $3 \mathrm{~h} \mathrm{p.i} \mathrm{(Horvath} \mathrm{et}$ al., 2011). In our experiments, infection occurred for $1 \mathrm{~h}$, not allowing sufficient time for the generation of filamentous UPEC. Our findings show that TFEB is activated in the first hour p.i, agreeing with the susceptibility of bacillary UPEC to degradation in the first 3 hours p.i prior to filament formation. Knowing this, it will be interesting to examine UPEC infection for longer periods of time, in order to determine how this morphology change, from bacillary to filamentous, might affect the behaviour of TFEB. Ultimately, our results show that both, EHEC and UPEC, are unable to prevent degradation in murine macrophages and thereby incapable of blocking TFEB activation.

\subsection{Salmonella must be alive to prevent TFEB nuclear localization}

Macrophages play an important role in protecting our bodies from foreign invaders. Most bacteria are rapidly killed inside phagocytes, however, pathogens like Salmonella are able to take advantage of the host defense mechanisms to avoid death through this process. Yet, the exact mechanism by which they do this is still unclear. Knowing TFEB's involvement in lysosomal-based degradation and its required nuclear localization, we decided to assess the subcellular localization of TFEB in macrophages infected with WT Salmonella to better 
understand how Salmonella prevents degradation(Nabar \& Kehrl, 2017; Pastore et al., 2016; Vega-rubin-de-celis, Peña-llopis, \& Konda, 2017). Our findings indicate that stationary phase WT Salmonella prevents TFEB nuclear translocation in the first hour p.i (Fig. 7). To further understand this process, we repeated the same experiment with heat-killed Salmonella. Heat denatures the proteins inside the bacteria, making these proteins non-functional, however, they still possess the PAMPs needed for PRR recognition and stimulation (Chow et al., 2015; Najibi et al., 2016). To our surprise, heat-killed Salmonella rapidly increases TFEB nuclear localization within the first hour of infection as seen in Figure 7. Therefore, we concluded that Salmonella actively represses TFEB activation, possibly due to the activation of virulence genes within SPIs.

\subsection{Salmonella regulates TFEB in a time and growth-dependent manner.}

Now that we have shown that Salmonella represses TFEB in the first hour p.i., we wanted to examine what happens at later times p.i. To test this, we decided to extend the period of infection from $1 \mathrm{~h}$, to 4 and $6 \mathrm{~h}$ in order to get a better understanding of TFEB manipulation by Salmonella. Similar to our previous results, in the first hour post infection, we saw TFEB repression, however at the later time points we observed TFEB slowly moving to the nucleus (Fig. 8). This suggests that a process during late infection activates TFEB. While we do not know why this might be currently, it could possibly implicate xenophagy. TFEB is the master regulator of lysosomal production and is needed for both phagocytosis and autophagy, since these processes require the cooperation of lysosomes (Settembre, C,, Di malta C., Polito VA, Garcia Arencibia, Vetrini F, Erding S, 2012). The host uses autophagy, more specifically xenophagy to target intracellular bacteria for lysosomal-based degradation, similar to phagocytosis (Ramos-Morales \& Ramos-Morales, 2012; Vural \& Kehrl, 2014). Salmonella 
seems to be able to prevent autophagy at the early stages of infection by targeting sirtuin-1 (Sirt1) and liver kinase B1 (LKB1) for degradation, preventing the activation of adenosine monophosphate kinase (AMPK) complex and evading autophagy(Ganesan et al., 2017) . Conversely, bacteria are able to manipulate host cell transport machinery to acquire intracellular nutrition needed for growth and survival (Popp et al., 2015). In this case, Salmonella is also able to trigger acute intracellular amino acid starvation due to host membrane damage, this will induce autophagy through the downregulation of mTORC1 and therefore increase TFEB activation to enhance lysosomal-based degradation (Tattoli et al., 2012). Tattoli et al., have also shown that Salmonella gets targeted for autophagy $4 \mathrm{~h}$ p.i, and that its able to control both amino acid starvation pathways and mTOR cellular trafficking, to down-regulate host defense mechanisms at later time points, although the exact mechanism is not yet clear (Tattoli et al., 2012). This notion of bacteria manipulating host autophagy machinery for their own benefit at different stages of infection, could possibly explain how TFEB nuclear translocation is suppressed at early time points, but at later time points becomes activated and shuttles to the nucleus as we see in Fig 8. Ultimately, it seems that Salmonella is manipulating TFEB in a timedependent manner by repressing TFEB at the early stages of infection, possibly to avoid degradation and establish its niche, but at later times, TFEB translocates to the nucleus most likely to enhance degradation, yet the exact reasoning behind this is still unknown.

Similar to the time-dependent activation of TFEB, we also observed that different growth phases of Salmonella have distinct capabilities in terms of virulence and possible avoidance of degradation. Late-log phase induces SPI-1 T3SS and effectors, which are required for invasion of non-phagocytes like epithelial cells (Sridhar \& Steele-mortimer, 2016). Our results show that 
SPI-1 induced Salmonella does not repress TFEB in the first few hours post infection (Fig. 9) and it agrees with the results seen by Najibi et al. in 2016, where late-log or late-exponential bacteria have the inability to repress TFEB (Najibi et al., 2016). In contrast, SPI-2 induced (stationary phase) bacteria, promotes SPI-2 T3SS expression and SPI-2 effectors needed for survival and replication (Chakravortty et al., 2005; Cirillo et al., 1998). We see that stationary phase bacteria have the ability to repress TFEB at early periods of infection as we showed in figures 7-9. These results suggest, that Salmonella growth phase conditions have different outcomes on TFEB activation, but most importantly, indicating a potential role of SPI-2 expression in the virulence of Salmonella (D'Costa et al., 2015; Garmendia et al., 2003; Wisner et al., 2012). Although it appears simple, we have some results showing that Salmonella virulence is more complex than SPI-1 and SPI-2 T3SSs expression, since Salmonella seems to have over 23 SPIs and some of them contribute to their virulence (Mitchell et al., 2016). We decided to test a SPI-2 mutant (ssaR) that lacks a structural protein essential for the assembly of the SPI-2 T3SS apparatus, therefore, a ssaR mutant is unable to deliver SPI-2 effector proteins into the host cytosol (Harrison et al., 2004). As seen in figure 14, the SPI-2 mutant is still able to partially prevent TFEB activation in the first hour p.i, even though it's unable to deliver SPI-2 effectors to the host cytosol, suggesting a possible collaboration in the virulence of Salmonella between different SPIs. This collaboration could in part be with SPI-1, since the double SPI1/SPI-2 stationary-phase mutant loses the ability to repress TFEB. These results provide evidence of the complexity of the Salmonella pathogenesis. 


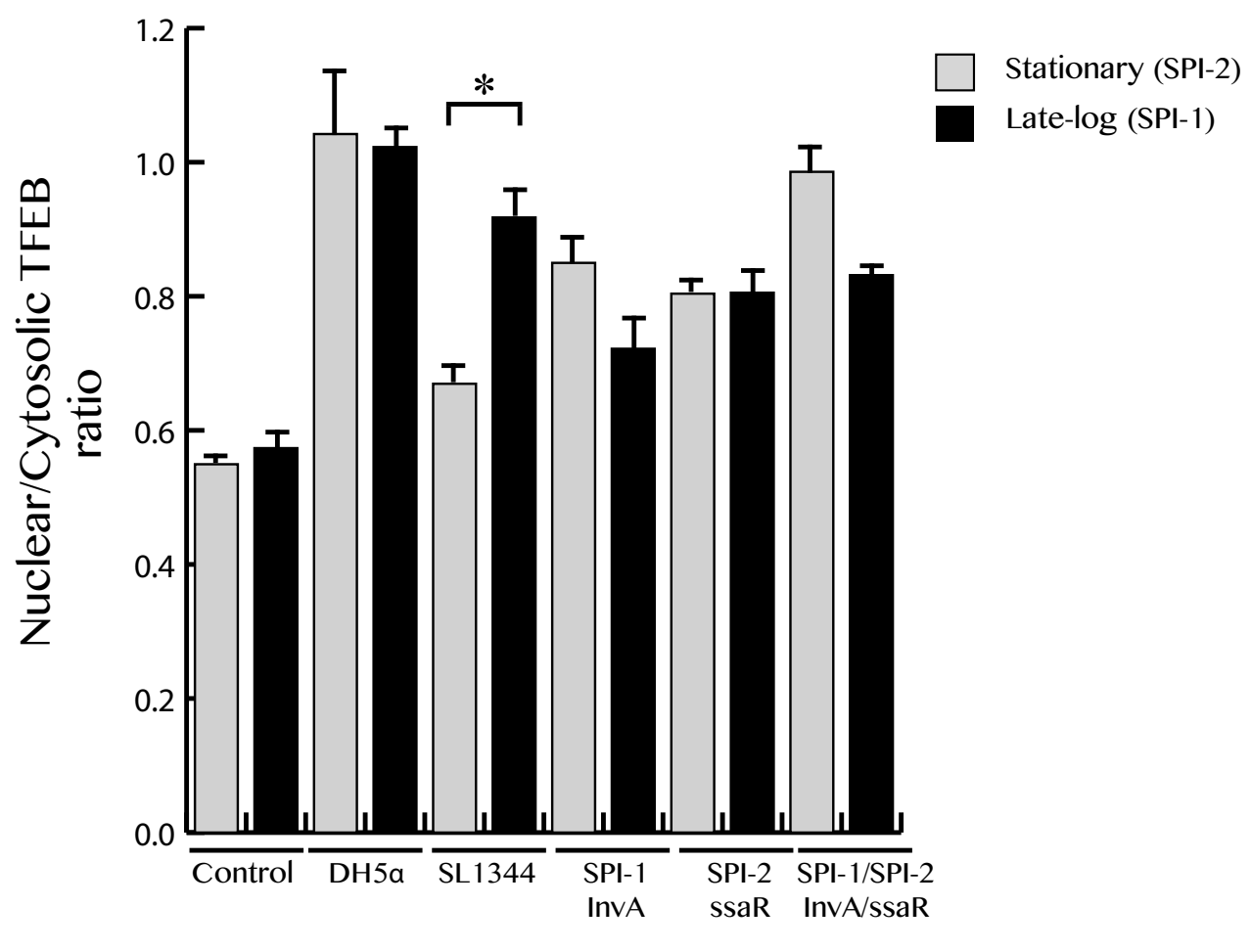

$1 \mathrm{~h}$

Figure 14. SPI-2 T3SS plays an important, yet partial role in the repression of

TFEB activation. RAW 264.7 macrophages were infected with stationary (Salmonella-SPI-2 induction) and late-log (Salmonella-SPI-1 induction) E.coli, WT Salmonella (SL1344), SPI-1 mutant invA, SPI-2 mutant ssaR and SPI-1/SPI-2 mutant (invA/ssaR) to determine the role of the different SPIs in TFEB suppression. Nuclear/cytosolic TFEB ratio was quantified for $1 \mathrm{~h}$ p.i. Data is based on three independent experiments with approximately 70 cells counted per condition per experiment. Data was statistically analyzed with ANOVA, followed by Tukey's HSD. * Significant $(\mathrm{p}>0.05)$ between the growth phases, 


\subsection{SPI-2 expression plays an important role on TFEB repression}

The ability of Salmonella to survive and replicate within macrophages and other phagocytes has been tightly associated with the SPI-2 T3SS and the expression of SPI-2 effectors (Brumell et al., 2001; Fields, Swanson, Haidaris, \& Heffron, 1986). One of our goals was to understand if this association also required the inhibition of TFEB, in order to ensure survival within the host. To do so, we obtained strains deficient in SPI-2 effectors: sopD2, sifA, slrp, sigD (sopB), ssPH2, sopA, pipB2 and SPI-1/SPI-2 regulator phoP. Stationary phase bacteria were used from this point on since it induces expression of SPI-2 T3SS and SPI-2 effectors. Cells infected with $\triangle \operatorname{sopD2}, \Delta$ sifA and $\triangle p h o P$ mutants showed significantly higher levels of TFEB nuclear localization compared to the other strains in the first hour p.i (Fig . 10). Both SifA and SopD2 are effectors that are involved in the trafficking and delivery of the SCV to the lysosome for degradation. SopD2 is a SPI-2 effector that contributes to the virulence of Salmonella by interfering with the endocytic pathway (D'Costa et al., 2015). Similar to other SPI-2 effectors, its expression is dependent on active ssrA/ssrB and PhoP/PhoQ two component regulatory systems, and it is induced at high levels compared to other SPI-2 effectors (Fig. 5) (Brumell et al., 2003). SopD2 function is necessary and sufficient to block endocytic cargo delivery to the lysosome for degradation (D'Costa et al., 2015). It does this by interacting with host GTPase Rab7 and impairing Rab7's ability to interact to its effectors RILP and FYCO1. This releases the SCV from host microtubules motors, allowing these microtubules to be hijacked and used by Salmonella for the induction of Salmonella-induced filaments (SIFs) (Brumell \& Grinstein, 2004; D’Costa et al., 2015). A strain deficient in effector SopD2 results in dramatic restoration of trafficking of the SCV to the lysosomes for lysosomal-based degradation (D'Costa et al., 2015). This could correspond to the increase in TFEB nuclear intensity 
observed, suggesting the SCV interacts with the Rab7-RILP complex and gets re-directed to the lysosome for degradation. Similar to SopD2, SifA is a SPI-2 effector, dependent on ssrA/ssrB, and PhoP/PhoQ two component regulatory systems (Wisner et al., 2012). SifA alters SCV processing in macrophages, it is required to maintain the integrity of the SCV and also to promote the formation of Salmonella-induced filaments that are used by the bacteria to disseminate infection (Rajashekar et al., 2014). Because of their inability to maintain intact SCVs, sifA mutants have a defect in replication and intracellular survival as seen by RamosMorales in 2012 (Brumell et al., 2001; Ramos-Morales \& Ramos-Morales, 2012). SifA seems to be partially responsible for the uncoupling of Rab7 from its effector RILP (Rab-Interacting lysosomal protein), indicating a possible collaboration between SopD2 and SifA to prevent Salmonella degradation (Harrison et al., 2004; Ramos-Morales \& Ramos-Morales, 2012). SifA defective mutant displays significantly attenuated virulence correlating with the premature activation of TFEB and its subsequent nuclear translocation observed in Fig. 10 and 11 (Harrison et al., 2004). On the other hand, the regulator PhoP is essential for the transition between SPI-1 and SPI-2 T3SS expression and its crucial for Salmonella's survival (Andino \& Hanning, 2015; Soncini, Vescovi, \& Groisman, 1995; Wisner et al., 2012). PhoQ is a histidine kinase able to sense environmental signals like low $\mathrm{pH}$, low magnesium concentration, or iron availability, which are some of the changes that occur during phagosome maturation of the SCV (Campos et al., 2004). Once these changes are sensed by PhoQ, PhoP negatively regulates the expressions of HilA, leading to the down-regulation of SPI-1 T3SS. At the same time, it binds to the promoter of $s s r B$ to promote the expression of the SsrB component of the two-component regulatory system that leads the expression of SPI-2 T3SS and SPI-2 effectors, which include SopD2 and SifA (Fig. 5). It is known that Salmonella phoP mutants are more susceptible to antimicrobial 
peptides and therefore more vulnerable to degradation, suggesting that the increase in TFEB nuclear translocation in our results could be in part responsible for this susceptibility (Fig. 10 and Fig. 11). All of these data suggest an important role of SPI-2 T3SS induction and SPI-2 effectors in escaping lysosomal degradation, although like mentioned before, Salmonella seems to use an interplay of effectors and machineries to ensure its survival inside the host, making this a more complicated topic.

\subsection{TFEB is important for bacterial degradation}

Given the striking TFEB repression by WT Salmonella, but TFEB activation in the isogenic mutants mentioned above, we questioned if Salmonella is actively repressing TFEB in order to ensure its own survival by preventing an increase in lysosomal-production, and therefore avoiding degradation. Previous research has shown that TFEB activation promotes lysosomalbased degradation of internalized targets (Gray et al., 2016; Settembre, C,, Di malta C., Polito VA, Garcia Arencibia, Vetrini F, Erding S, 2012). We speculated this is the case, and decided to test this through the use of a gentamicin-protection assay. This assay has been widely used for the study of intracellular pathogens ex-vivo, since certain pathogens including Salmonella, evade killing by some antibiotics that are unable to penetrate eukaryotic cells like, gentamicin, thereby allowing to examine the survival and growth of internalized pathogens (Wu et al., 2014). We infected WT RAW macrophages and macrophages lacking TFEB (TFEB-/-) with nonpathogenic E.coli (DH5 $)$ and WT Salmonella in order to test TFEB's involvement in the clearance of bacteria, keeping in mind that non-pathogenic DH5 $\alpha$ activates TFEB within the first hour of infection and WT Salmonella actively prevents its nuclear translocation (Fig. 7-8). We observed that WT macrophages are capable of eliminating DH5 $\alpha$ after 4 hours of phagocytosis, however, for Salmonella the bacteria survived and replicated (Fig. 12). In contrast, macrophages 
lacking TFEB were unable to eliminate either DH5 $\alpha$ or WT Salmonella, with Salmonella replicating somehow better inside the TFEB-/- host compared to the WT host, although this difference is insignificant. As we have seen before, WT Salmonella blocks TFEB activation, thus the deletion of TFEB does not seem to have a vast effect on Salmonella growth and/or survival. These results indicate a potential and promising role of TFEB activation in the elimination of bacteria.

\subsection{TFEB pre-activation increases the chances of clearance of infection}

Previous research in our lab has uncovered a novel phenomenon showing that uptake of IgG immune complexes through the FcyR-mediated endocytosis trains macrophages into becoming better killers by increasing lysosome production and therefore lysosomal-based degradation of internalized targets (Gray et al., 2016). We decided to test this phenomenon in the clearance of Salmonella. In order to do this, we repeated the previous gentamicin protection assay, in WT macrophages and TFEB-KO RAW macrophages, with pre-activation of TFEB through the uptake of IgG opsonized beads via Fc $\gamma \mathrm{R}$ binding prior to infection, and also by inhibiting mTORC1 with the use of rapamycin(Gray et al., 2016; Weichhart, Hengstschläger, \& Linke, 2015). Data was normalized to uptake and non-activated treatment, seeing how we saw similar results to our previous section, seeing an increase in DH5 $\alpha$ degradation in the WT, but not in the TFEB-KO cells, whereas Salmonella survived in both cell lines. For both preactivated treatments, we saw a significant decrease in bacterial survival for WT Salmonella in the WT macrophages, similar in the DH5 $\alpha$ infected cells, although the difference was nonsignificant. These experiments should be repeated for reliability. In TFEB-KO cells, the reduction in bacterial survival was not observed for DH5 $\alpha$, although for WT Salmonella it 
dropped slightly, implying the possibility that Salmonella needs and manipulates TFEB for its own survival (Fig. 13). Rapamycin treatment revealed an exciting treatment option for bacterial infection due to its active FDA (Federal Drug Agency) approval. Although the use of rapamycin to fight infections may be complicated because it is also used as an immunosuppressant, this observation alludes to the complex roles of mTORC1 in cellular and physiological functions (Settembre et al., 2012). The use of rapamycin to activate TFEB suggests the potential use of small drugs as delivery mechanisms to activate TFEB, although specific agonists of TFEB are not yet known. Manipulating mTORC1 through inhibition might not be the only way to enhance TFEB activation since TFEB has a complex regulation pattern as seen in Fig 2; there are other pathways that might have an effect on the activation of TFEB during infection, including the PLC-PKD and AMPK-LKB1-Sirt1 pathways (Najibi et al., 2016). Together, these data showcase the important role of TFEB in the clearance of bacterial infections and its potential use as a therapeutic target.

\subsection{Concluding Remarks}

Collectively, the data presented in this thesis show that TFEB activation is needed to enhance lysosomal-based degradation of bacteria. In the case of Salmonella, it seems to actively prevent TFEB activation in a time and growth-dependent manner, most likely to avoid lysosomal-based degradation. We have identified 2 SPI-2 effectors, SopD2 and SifA, and a response regulator PhoP, which possibly have a functional role in the repression of TFEB activation during Salmonella pathogenesis. Finally, we have learned that pre-activation of TFEB is sufficient and necessary to prevent Salmonella survival, supporting our hypothesis that Salmonella might be manipulating TFEB activation to enhance its own survival intracellularly. 
These findings provide a promising role of TFEB as a therapeutic target for the treatment of infections. Knowing that the mTORC1 pathway, the PLC-PKD and the AMPK-LKB1-Sirt1 pathways are implicated in the activation of TFEB, we still need to determine the exact pathway that is manipulated during a Salmonella infection. Please see final working model of suggested Salmonella TFEB manipulation (Fig. 15) 


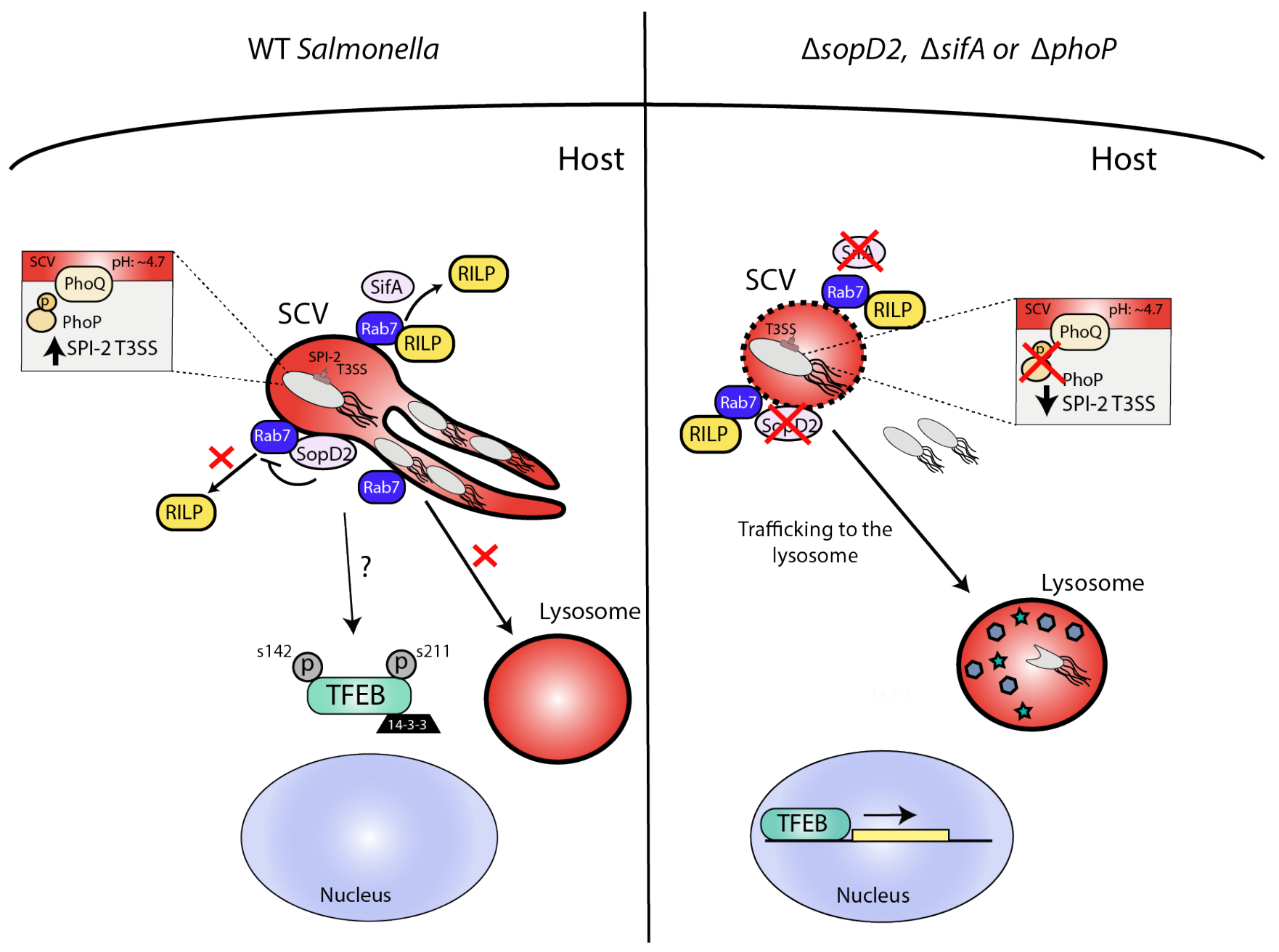

Figure 15. Suggested final model of TFEB regulation by Salmonella. WT Salmonella represses TFEB activation at early points of infection by possibly using SPI-2 effectors SopD2 and SifA, and regulator PhoP, to avoid delivery of the SCV to the lysosome for lysosomal-based proteolysis. Strains lacking SopD2, SifA and/or PhoP, lack the ability to repress TFEB leading to an increase in lysosome-based degradation through phagocytosis. These mutants are unable to prevent Rab7 and RILP association, delivering the SCV to the lysosome for degradation and causing TFEB activation. 


\section{Future Directions}

\subsection{Determine the mechanisms of action by which Salmonella interferes with TFEB activation.}

Many studies have focused on finding pathways targeted by Salmonella during infection. As mentioned before, TFEB is regulated by multiple pathways including mTORC1-dependent and independent pathways. One mTORC1-dependent pathway that was recently published is the AMPK-LKB1-Sirt1. At early time periods of infection, macrophages lose energy, leading to the activation of the AMPK complex, however, Salmonella targets for degradation two components of the AMPK complex, LKB1 and Sirt-1 in a SPI-2 dependent manner, resulting in mTOR activation and ceasing of autophagy, which could potentially explain decreased TFEB nuclear translocation at early times post infection (Ganesan et al., 2017). mTORC1-independent pathways include the PI3K-AKT pathways. AKT inhibition results in TFEB nuclear translocation independent of mTORC1 (Palmieri, Pal, Nelvagal, et al., 2017). AKT is a serine/threonine kinase that is involved in survival and apoptosis (Sbano et al., 2017). It plays an important role in the integration of signals from growth factors that will affect mTORC1, however, it is surprising that AKT inhibition does not inhibit mTORC1 activity, possibly due to the Ras-ERK pathway that acts in parallel to the PI3K-AKT pathway keeping mTORC1 active (Palmieri, Pal, Nelvagal, et al., 2017). AKT is also involved in the degradation of Sirt-1, leading to the repression of autophagy in the AMKP-LKB1-Sirt11 pathway (Ganesan et al., 2017). On the other hand, there's the PLC-PKD pathway, an mTORC1-independent pathway that seems to be induced upon pathogen recognition by an unknown receptor, although studies have shown PKD1 is activated by TLRs and LPS binding (Y. Kim et al., 2010). This binding causes a signaling cascade through the MyD-88-dependent pathway that requires $\mathrm{PKD}$ for the activation 
of NF-kB which is important for a pro-inflammatory response (Najibi et al., 2016). Although poorly studied, there are many pathways that are being brought to light that connect TFEB with the lysosomal-based degradation of pathogens, therefore is necessary to understand the pathway that Salmonella manipulates to prevent degradation.

Additionally, it is important to identify the exact effector/proteins that contribute to Salmonella's TFEB manipulation in order to understand their contribution to the repression of TFEB. Like mentioned before, this is not an easy task, since Salmonella does not only count on SPI-1 and SPI-2 for virulence, having more than 23 SPIs, with some of them contributing to the pathogenesis of different Salmonella serotypes, including S. typhimurium (Mitchell et al., 2016). Most of these SPIs role in Salmonella virulence are unknown. However, in this study, we have identified two SPI-2 effectors (SopD2, SifA) and one regulator (PhoP) that seem to play a role in the ability of Salmonella to repress TFEB activation. PhoP is responsible for the transition of SPI-1 to SPI-2, and also plays a role on SPI-2 expression. It might prevent Salmonella transitioning from SPI-1 to SPI-2 T3SS expression, making Salmonella more susceptible to degradation. It can also serve as a waiting period for the expression of SPI-2 effectors needed for survival and replication. This could be tested using an OmpR mutant that also contributes to the expression of SPI-2 effectors (Fig. 4). If this is the case, an OmpR/PhoP double-mutant is expected to show a higher TFEB nuclear localization compared to the PhoP or OmpR mutant. SPI-2 protein expression could be confirmed by using Western blot analysis in order to see if the PhoP mutant is preventing or reducing SPI-2 gene expression. SopD2 and SifA are SPI-2 effectors involved in trafficking to the lysosome for degradation, they might be acting together or in association with other effectors, to prevent degradation of the bacteria by blocking the 
delivery of the SCV to the lysosomes for degradation. To test this, a DQ-BSA assay measuring the proteolytic activity of lysosomes might be helpful to determine if fluorescently labelled bacteria is being delivered to the lysosome for degradation, this could be determined by looking at co-localization of the DQ-BSA with the fluorescently-labelled bacteria. Ultimately, this will provide some important clues into understanding the mechanism or mechanisms by which Salmonella manipulates TFEB and the combination of effectors that might play a role in this process.

\subsection{Determine the role of TFE3 in pathogen clearance}

TFE3 is a member of the MITF subfamily along with TFEB and it also regulates the expression of lysosomal genes. Similarly to TFEB, TFE3 binds to CLEAR elements and induces lysosomal biogenesis and autophagy (José A Martina \& Puertollano, 2016). In some cell types, both transcription factors seem to play redundant roles in terms of their ability to induce expression of lysosomal genes, however, both must be present for a maximal biological response (José A Martina \& Puertollano, 2016; Pastore et al., 2016). TFE3 is activated by amino acid depletion by mTORC1, however the mechanism of regulation of TFE3 by other stressors, like TFEB, can be independent of mTORC1 activity (José A Martina \& Puertollano, 2016). Therefore, it is clear that TFE3 plays an important part in cellular response and adaptation to stress, including infection. Since TFE3 behaves similarly to TFEB in some situations, and knowing that TFEB plays an important role in the clearance of bacteria, future research should focus on investigating the role of TFE3 in clearance of infection and its relationship to TFEB. For this, similarly to TFEB-KO cells, TFE3-KO and TFEB/TFE3-double knock out (DKO) RAW macrophages could be used during infection and survival assays as done here with TFEBKO cells. This would allow us to see if TFE3 also has a potential role in the clearance of 
infections, and if TFEB and TFE3 show additive or synergistic effects during phagocytosis and infection.

\subsection{In vivo function of TFEB in the clearance of infections}

In this study, much of the work focused on exploring the direct response of Salmonella infection on RAW macrophages and looking for TFEB activation in vitro. Now that we have established the importance of TFEB in vitro, it is necessary to address the potential use of TFEB in vivo to ensure TFEB activation is physiologically relevant. Mice depleted of $t f e b, t f e 3$ or both, have bene generated by the lab of Dr. Rosa Puertollano at NIH. Pastore et al, obtained Bonemarrow derived macrophages (BMDM) from these mice and they were tested for TFEB and TFE3 activation upon LPS stimulation (Pastore et al., 2016). As mentioned before, both TFEB and TFE3, have a synergistic effect on lysosomal biogenesis and cytokine production, therefore it is important to test E.coli and Salmonella infections in these mice, in order see if the lack of TFEB and/or TFE3 reduces or prevents the ability of mice to clear infections. Following our in vitro results, it is expected that $t f e b$ and $t f e 3$ mice, will lose some ability to clear infection when infected with both E.coli and WT Salmonella, compared to the double knockout (DKO) that will be unable to clear either infection. This could also potentially include the rapamycin and torin1 treatments on WT mice, to determine enhancement of degradation as seen in vitro with rapamycin-treated macrophages. Where we expect WT-activated macrophages to increase their lysosomal-proteolysis and clear infections faster. This experiment is essential to determine the potential use of TFEB as a therapeutic target that drives bacterial killing. 


\section{References}

Aderem, A. (2003). Phagocytosis and the inflammatory response. J.Infect.Dis., 187 Suppl(00221899 (Print)), S340-S345. http://doi.org/JID21046 [pii] \r10.1086/374747

Andino, A., \& Hanning, I. (2015). Salmonella enterica: Survival, colonization, and virulence differences among serovars. Scientific World Journal, 2015(Table 3). http://doi.org/10.1155/2015/520179

Appelqvist, H., Wäster, P., Kågedal, K., \& Öllinger, K. (2013). The lysosome: From waste bag to potential therapeutic target. Journal of Molecular Cell Biology, 5(4), 214-226. http://doi.org/10.1093/jmcb/mjt022

Ashida, H., Mimuro, H., \& Sasakawa, C. (2015). Shigella manipulates host immune responses by delivering effector proteins with specific roles. Frontiers in Immunology, 6(MAY), 112. http://doi.org/10.3389/fimmu.2015.00219

Beckman, H., \& Kadeseh, T. (1991). The leucine zipper of TFE3 dictates helix-loop-helix dimerization specificity. Genes and Development, 5, 1057-1066.

Bijlsma, J. J. E., \& Groisman, E. A. (2005). The PhoP / PhoQ system controls the intramacrophage type three secretion system of Salmonella enterica. Molecular Microbiology, 57(1), 85-96. http://doi.org/10.1111/j.1365-2958.2005.04668.x

Bosisio, D., Polentarutti, N., Sironi, M., Bernasconi, S., Miyake, K., Webb, G. R., ... Muzio, M. (2002). Stimulation of toll-like receptor 4 expression in human mononuclear phagocytes by interferon-gamma: a molecular basis for priming and synergism with bacterial lipopolysaccharide. Blood, 99(9), 3427-3431.

Botelho, R. J., \& Grinstein, S. (2011). Phagocytosis. Current Biology, 21(14), 533-538. http://doi.org/10.1016/j.cub.2011.05.053

Brumell, J. H., \& Grinstein, S. (2004). Salmonella redirects phagosomal maturation. Current Opinion in Microbiology, 7(1), 78-84. http://doi.org/10.1016/j.mib.2003.12.005

Brumell, J. H., Kujat-Choy, S., Brown, N. F., Vallance, B. A., Knodler, L. A., \& Finlay, B. B. (2003). SopD2 is a novel type III secreted effector of Salmonella typhimurium that targets late endocytic compartments upon delivery into host cells. Traffic, 4(1), 36-48. http://doi.org/10.1034/j.1600-0854.2003.40106.x

Brumell, J. H., Rosenberger, C. M., Gotto, G. T., Marcus, S. L., \& Finlay, B. B. (2001). SifA permits survival and replication of Salmonella typhimurium in murine macrophages. Cellular Microbiology, 3(2), 75-84. http://doi.org/10.1046/j.1462-5822.2001.00087.x

Cabec, V. Le, Carréno, S., Moisand, A., Bordier, C., Maridonneau-parini, I., Bordier, C., \& 
Maridonneau-parini, I. (2017). Complement Receptor 3 (CD11b/CD18) Mediates Type I and Type II Phagocytosis During Nonopsonic and Opsonic Phagocytosis, Respectively. The Journal of Immunology, 3, 2002-2009. http://doi.org/10.4049/jimmunol.169.4.2003

Campos, M. a, Vargas, M. a, Regueiro, V., Llompart, C. M., Albertí, S., \& José, A. (2004). Capsule Polysaccharide Mediates Bacterial Resistance to Antimicrobial Peptides Capsule Polysaccharide Mediates Bacterial Resistance to Antimicrobial Peptides. Infection and Immunity, 72(12), 7107-7114. http://doi.org/10.1128/IAI.72.12.7107

Cantalupo, G., Alifano, P., Roberti, V., Bruni, C. B., \& Bucci, C. (2001). Rab-interacting lysosomal protein ( RILP ): the Rab7 effector required for transport to lysosomes. $E M B O$, 20(4), 683-693.

Chakravortty, D., Rohde, M., Jäger, L., Deiwick, J., \& Hensel, M. (2005). Formation of a novel surface structure encoded by Salmonella Pathogenicity Island 2. The EMBO Journal, 24(11), 2043-2052. http://doi.org/10.1038/sj.emboj.7600676

Chow, S. C., Gowing, S. D., Cools-lartigue, J. J., Chen, C. B., Berube, J., Yoon, H., ... Ferri, L. E. (2015). Gram negative bacteria increase non-small cell lung cancer metastasis via tolllike receptor 4 activation and mitogen-activated protein kinase phosphorylation. International Journal of Cancer. Journal International Du Cancer, 136, 1341-1350. http://doi.org/10.1002/ijc.29111

Cirillo, D. M., Valdivia, R. H., Monack, D. M., \& Falkow, S. (1998). Macrophage-dependent induction of the Salmonellapathogenicity island 2 type III secretion system and its role in intracellular survival. Molecular Microbiology, 30(1), 175-188. Retrieved from http://doi.wiley.com/10.1046/j.13652958.1998.01048.x\%5Cnpapers2://publication/doi/10.1046/j.1365-2958.1998.01048.x

D’Costa, V. M., Braun, V., Landekic, M., Shi, R., Proteau, A., McDonald, L., ... Brumell, J. H. (2015). Salmonella Disrupts Host Endocytic Trafficking by SopD2-Mediated Inhibition of Rab7. Cell Reports, 12(9), 1508-1518. http://doi.org/10.1016/j.celrep.2015.07.063

Dayam, R. M., Saric, A., Shilliday, R. E., \& Botelho, R. J. (2015). The Phosphoinositide-Gated Lysosomal $\mathrm{Ca}^{2+}$ Channel, TRPML1, Is Required for Phagosome Maturation. Traffic, 16(9), 1010-1026. http://doi.org/10.1111/tra.12303

Ellermeier, C. D., Ellermeier, J. R., \& Slauch, J. M. (2005). HilD , HilC and RtsA constitute a feed forward loop that controls expression of the SPI1 type three secretion system regulator hilA in Salmonella enterica serovar Typhimurium. Molecular Microbiology, 57(3), 691705. http://doi.org/10.1111/j.1365-2958.2005.04737.x

Ellermeier, J. R., \& Slauch, J. M. (2007). Adaptation to the host environment: regulation of the SPI1 type III secretion system in Salmonella enterica serovar Typhimurium. Current 
Opinion in Microbiology, 10, 24-29. http://doi.org/10.1016/j.mib.2006.12.002

Fairn, G. D., \& Grinstein, S. (2012). How nascent phagosomes mature to become phagolysosomes. Trends in Immunology, 33(8), 397-405.

http://doi.org/10.1016/j.it.2012.03.003

Fields, P. I., Swanson, R. V, Haidaris, C. G., \& Heffron, F. (1986). Mutants of Salmonella typhimurium that cannot survive within the macrophage are avirulent. PNAS, 83(July), 5189-5193.

Fisher, D. E., Carr, C. S., Parent, L. A., \& Sharp, P. A. (1991). TFEB has D NA-binding and oligomerization properties of a unique helix-loop-helix / leucine-zipper family. Genes and Development, 5, 2342-2353.

Fisher, D. E., Parentt, L. A., \& Sharpt, P. A. (1992). helix-loop-helix/leucine. Proceedings of the National Academy of Sciences of the United States of America, 89(December), 1177911783.

Forest, C. G., Ferraro, E., Sabbagh, S. C., \& Daigle, F. (2010). Intracellular survival of Salmonella enterica serovar Typhi in human macrophages is independent of Salmonella pathogenicity island (SPI)-2. Microbiology, 156(12), 3689-3698.

http://doi.org/10.1099/mic.0.041624-0

Galan, J. E. (2001). S ALMONELLA I NTERACTIONS WITH H OST C ELLS : Type III Secretion at Work. Biology, 17, 53-86. http://doi.org/10.1146/annurev.cellbio.17.1.53

Galan, J. E., Ginocchio, C., \& Costeas, P. (1992). Molecular and functional characterisation of the Salmonella invasion gene inv A : Homology of InvA to members of a new protein family. J. Bacteriol., 174(13), 4338-4349.

Ganesan, R., Hos, N. J., Gutierrez, S., Fischer, J., Robinson, N., Stepek, M., ... Kro, M. (2017). Salmonella Typhimurium disrupts Sirt1 / AMPK checkpoint control of mTOR to impair autophagy. PLOS Pathogens, 13(2), 1-22. http://doi.org/10.1371/journal.ppat.1006227

Garmendia, J., Beuzón, C. R., Ruiz-Albert, J., \& Holden, D. W. (2003). The roles of SsrA-SsrB and OmpR-EnvZ in the regulation of genes encoding the Salmonella typhimurium SPI-2 type III secretion system. Microbiology, 149(9), 2385-2396.

http://doi.org/10.1099/mic.0.26397-0

Gray, M. A., Choy, C. H., Dayam, R. M., Ospina-Escobar, E., Somerville, A., Xiao, X., ... Botelho, R. J. (2016). Phagocytosis Enhances Lysosomal and Bactericidal Properties by Activating the Transcription Factor TFEB. Current Biology. http://doi.org/10.1016/j.cub.2016.05.070

Groisman, E. A. (2001). The Pleiotropic Two-Component Regulatory System PhoP-PhoQ †. 
Journal of Bacteriology, 183(6), 1835-1842. http://doi.org/10.1128/JB.183.6.1835

Haas, A. (2007). The Phagosome : Compartment with a License to Kill. Traffic, 311-330. http://doi.org/10.1111/j.1600-0854.2006.00531.x

Harrison, R. E., Bucci, C., Salento, U., Harrison, R. E., Brumell, J. H., Khandani, A., ... Grinstein, S. (2004). Salmonella Impairs RILP Recruitment to Rab7 during Maturation of Invasion Vacuoles Salmonella Impairs RILP Recruitment to Rab7 during Maturation of Invasion Vacuoles. Mol. Biol. Cell, 15(August 2004), 3146-3154. http://doi.org/10.1091/mbc.E04

Hensel, M., Bakteriologie, L., \& Pettenkofer-institut, M. Von. (2000). Salmonella pathogenicity island 2. Molecular Microbiology, 36(5), 1015-1023. http://doi.org/10.1046/j.13652958.2000.01935.x

Horvath, D. J., Li, B., Casper, T., Partida-Sanchez, S., Hunstad, D. A., Hultgren, S. J., \& Justice, S. S. (2011). Morphological plasticity promotes resistance to phagocyte killing of uropathogenic Escherichia coli. Microbes and Infection, 13(5), 426-437. http://doi.org/10.1016/j.micinf.2010.12.004

Ishida, Y., Nayak, S., Mindell, J. A., \& Grabe, M. (2013). A model of lysosomal pH regulation. The Journal of General Physiology, 705-720. http://doi.org/10.1085/jgp.201210930

Italiani, P., \& Boraschi, D. (2014). From monocytes to M1 / M2 macrophages : phenotypical vs . functional differentiation. Frontiers in Immunology, 5(October), 1-22. http://doi.org/10.3389/fimmu.2014.00514

Janeway, C. A. (2001). How the immune system works to protect the host from infection : A personal view. PNAS, 98(13), 7461-7468.

Janssens, S., \& Beyaert, R. (2003). Role of Toll-Like Receptors in Pathogen Recognition. Clinical Microbiology Reviews, 16(4), 637-646. http://doi.org/10.1128/CMR.16.4.637

Kim, S. G., Buel, G. R., \& Blenis, J. (2013). Nutrient regulation of the mTOR Complex 1 signaling pathway. Molecules and Cells, (March), 1-11. http://doi.org/10.1007/s10059-013$0138-2$

Kim, Y., Park, J., \& Brand, D. D. (2010). Protein Kinase D1 Is Essential for the Proinflammatory Response Induced by Hypersensitivity Pneumonitis-Causing Thermophilic Actinomycetes Saccharopolyspora rectivirgula. J Immunol, (184), 3145-3156. http://doi.org/10.4049/jimmunol.0903718

Kuhle, V., \& Hensel, M. (2004). Cellular microbiology of intracellular Salmonella enterica: Functions of the type III secretion system encoded by Salmonella pathogenicity island 2. Cellular and Molecular Life Sciences, 61(22), 2812-2826. http://doi.org/10.1007/s00018- 
$004-4248-\mathrm{z}$

Lai, X., Xu, Y., Chen, X., \& Ren, Y. (2015). Macrophage cell death upon intracellular bacterial infection Xin-He. Macrophage (Houst).

Laskin, D. L. (2009). Battle of Forces. Chem Res Toxicol., 22(8), 1376-1385. http://doi.org/10.1021/tx900086v.Macrophages

Lu, N., \& Zhou, Z. (2013). Membrane Trafficking and Phagosome Maturation During the Clearance of Apoptotic Cells. Int Rev Cel Mol Biol., 293, 269-309. http://doi.org/10.1016/B978-0-12-394304-0.00013-0.Membrane

Mandell, G. L. (1973). Interaction of Intraleukocytic Bacteria and Antibiotics. J. Clin. Invest., 52(January), 1673-1679.

Martina, J. A., Diab, H. I., Huiqing, L., \& Puertollano, R. (2015). Novel roles for the MiTF/TFE family of transcription factors in organelle biogenesis, nutrient sensing, and energy homeostasis. Cell Mol. Life Sci., 71(13), 2483-2497. http://doi.org/10.1007/s00018-0141565-8.Novel

Martina, J. A., \& Puertollano, R. (2016). TFEB and TFE3: the art of multitasking under stress conditions. Transcription, 1264(February), 00-00.

http://doi.org/10.1080/21541264.2016.1264353

Miao, Y., Li, G., Zhang, X., Xu, H., \& Abraham, S. N. (2015). A TRP channel senses lysosome neutralization by pathogens to trigger their expulsion. Cell, 161(6), 1306-1319. http://doi.org/10.1016/j.cell.2015.05.009

Mitchell, G., Chen, C., Portnoy, D. A., \& Biology, C. (2016). Strategies used by bacteria to grow in macrophages. Microbiol Spectr., 4(3). http://doi.org/10.1128/microbiolspec.MCHD0012-2015.Strategies

Mogensen, T. H. (2009). Pathogen recognition and inflammatory signaling in innate immune defenses. Clinical Microbiology Reviews, 22(2), 240-273. http://doi.org/10.1128/CMR.00046-08

Murray, P. J., \& Wynn, T. A. (2011). Protective and pathogenic functions of macrophage subsets. Nature Reviews. Immunology, 11(11), 723-37. http://doi.org/10.1038/nri3073

Nabar, N. R., \& Kehrl, J. H. (2017). The Transcription Factor EB Links Cellular Stress to the Immune Response. YJBM, 90, 301-315.

Najibi, M., Labed, S. A., Visvikis, O., \& Irazoqui, J. E. (2016). An Evolutionarily Conserved PLC-PKD-TFEB Pathway for Host Defense. Cell Reports, 15(8), 1-15. http://doi.org/10.1016/j.celrep.2016.04.052 
Newman, M.-A., Sundelin, T., Nielsen, J. T., \& Erbs, G. (2013). MAMP (microbe-associated molecular pattern) triggered immunity in plants. Frontiers in Plant Science, 4(May), 139. http://doi.org/10.3389/fpls.2013.00139

Olson, P. D., \& Hunstad, D. A. (2016). Subversion of Host Innate Immunity by Uropathogenic Escherichia coli. Pathogens, 5(2), 1-10. http://doi.org/10.3390/pathogens5010002

Palmieri, M., Impey, S., Kang, H., di Ronza, A., Pelz, C., Sardiello, M., \& Ballabio, A. (2011). Characterization of the CLEAR network reveals an integrated control of cellular clearance pathways. Human Molecular Genetics, 20(19), 3852-3866.

http://doi.org/10.1093/hmg/ddr306

Palmieri, M., Pal, R., Nelvagal, H. R., Lotfi, P., Stinnett, G. R., Seymour, M. L., ... Sardiello, M. (2017). mTORC1-independent TFEB activation via Akt inhibition promotes cellular clearance in neurodegenerative storage diseases. Nature Communications, 8(May 2016), 14338. http://doi.org/10.1038/ncomms14338

Palmieri, M., Pal, R., \& Sardiello, M. (2017). AKT modulates the autophagy-lysosome pathway via TFEB. Cell Cycle, 4101(June), 1-2. http://doi.org/10.1080/15384101.2017.1337968

Paquet, D., Kwart, D., Chen, A., Sproul, A., Jacob, S., Teo, S., ... Psen, A. P. P. (2016). Efficient introduction of specific homozygous and heterozygous mutations using CRISPR/Cas9. Nature, 533(7601), 125-129. http://doi.org/10.1038/nature17664

Pastore, N., Brady, O. A., Diab, H. I., Martina, J. A., Sun, L., Huynh, T., ... Puertollano, R. (2016). TFEB and TFE3 cooperate in the regulation of the innate immune response in activated macrophages. Autophagy, 12(8), 1240-1258. http://doi.org/10.1080/15548627.2016.1179405

Pavlova, B., Volf, J., Ondrackova, P., Matiasovic, J., Stepanova, H., Crhanova, M., ... Rychlik, I. (2011). SPI-1-encoded type III secretion system of Salmonella enterica is required for the suppression of porcine alveolar macrophage cytokine expression. Veterinary Research, 42(1), 16. http://doi.org/10.1186/1297-9716-42-16

Pegues, D., Hantman, M., Behlau, I., \& Miller, S. I. (1995). PhoP / PhoQ transcriptional repression of Salmonella typhimurium invasion protein secretion genes: evidence for a role in protein secretion. Molecular Microbiology, 17(1), 169-181. Retrieved from http://onlinelibrary.wiley.com/doi/10.1111/j.1365-2958.1995.mmi_17010169.x/abstract

Pena-Llopis, S., Vega-rubin-de-celis, S., Schwartz, J. C., Wolff, N. C., Tran, T. A. T., Zou, L., ... Brugarolas, J. (2011). Regulation of TFEB and V-ATPases by mTORC1 . EMBO, 30(16), 3242-3258. http://doi.org/10.1038/emboj.2011.257

Picking, W. L., Nishioka, H., Hearn, P. D., Baxter, M. A., Harrington, A. T., Blocker, A., \& Picking, W. D. (2005). IpaD of Shigella flexneri is independently required for regulation of 
Ipa protein secretion and efficient insertion of IpaB and IpaC into host membranes.

Infection and Immunity, 73(3), 1432-1440. http://doi.org/10.1128/IAI.73.3.1432-1440.2005

Poirier, K., Faucher, S. P., Béland, M., Brousseau, R., Gannon, V., Martin, C., ... Daigle, F. (2008). Escherichia coli O157:H7 survives within human macrophages: Global gene expression profile and involvement of the Shiga toxins. Infection and Immunity, 76(11), 4814-4822. http://doi.org/10.1128/IAI.00446-08

Popp, J., Noster, J., Busch, K., Kehl, A., Hellen, G., \& Hensel, M. (2015). Role of Host CellDerived Amino Acids in Nutrition of Intracellular Salmonella enterica. Infect Immun, 83(12), 4466-4475. http://doi.org/10.1128/IAI.00624-15.Editor

Rajashekar, R., Liebl, D., Chikkaballi, D., Liss, V., \& Hensel, M. (2014). Live Cell imaging reveals novel functions of Salmonella enterica SPI2-T3SS effector proteins in remodeling of the host cell endosomal system. PLoS ONE, 9(12), 1-29. http://doi.org/10.1371/journal.pone.0115423

Ramos-Morales, F., \& Ramos-Morales, F. (2012). Impact of Salmonella enterica Type III Secretion System Effectors on the Eukaryotic Host Cell. ISRN Cell Biology, 2012, 1-36. http://doi.org/10.5402/2012/787934

Roczniak-Ferguson, A., S. Petit, C., Froehlich, F., Qian, S., Ky, J., Angarola, B., ... Ferguson, S. (2012). The Transcription Factor TFEB Links mTORC1 Signaling to Transcriptional Control of Lysosome NIH Public Access. Science Signaling, 5 (228)(February 2014). http://doi.org/10.1126/scisignal.2002790

Sansonetti, P. (2001). Phagocytosis of bacterial pathogens: implications in the host response. Seminars in Immunology, 13(6), 381-390. http://doi.org/10.1006/smim.2001.0335

Sardiello, M. (2016). Transcription factor EB: from master coordinator of lysosomal pathways to candidate therapeutic target in degenerative storage diseases. Annals of the New York Academy of Sciences, 1371(1), 3-14. http://doi.org/10.1111/nyas.13131

Sbano, L., Bonora, M., Marchi, S., Baldassari, F., Medina, D. L., Ballabio, A., ... Pinton, P. (2017). TFEB-mediated increase in peripheral lysosomes regulates store-operated calcium entry. Scientific Reports, 7(January), 40797. http://doi.org/10.1038/srep40797

Schroeder, G. N., \& Hilbi, H. (2008). Molecular pathogenesis of Shigella spp.: Controlling host cell signaling, invasion, and death by type III secretion. Clinical Microbiology Reviews, 21(1), 134-156. http://doi.org/10.1128/CMR.00032-07

Schwake, M., \& Schr, B. (2013). Lysosomal Membrane Proteins and Their Central Role. Traffic, 739-748. http://doi.org/10.1111/tra.12056

Settembre, C,, Di malta C., Polito VA, Garcia Arencibia, Vetrini F, Erding S, et al. (2012). 
Transcription factor EB: A central regulator of both the autophagosome and lysosome. Hepatology, 55, 1632-1633. http://doi.org/10.1002/hep.25619

Settembre, C., Fraldi, A., Medina, D. L., Ballabio, A., \& Children, T. (2015). Signals for the lysosomes: a control center for cellular clearance and energy metabolism. Nat Rev Mol Cell Biol, 14(5), 283-296. http://doi.org/10.1038/nrm3565.Signals

Settembre, C., Polito, V. A., Arencibia, M. G., Vetrini, F., Erdin, S., Erdin, S. U., ... Ballabio, A. (2010). TFEB Links Autophagy to Lysosomal Biogenesis. Science, 332(6036), 1429-1433.

Settembre, C., Zoncu, R., Medina, D. L., Vetrini, F., Erdin, S., Erdin, S., ... Ballabio, A. (2012). A lysosome-to-nucleus signalling mechanism senses and regulates the lysosome via mTOR and TFEB. The European Molecular Biology Organization Journal, 31(5), 1095-108. http://doi.org/10.1038/emboj.2012.32

Shimada, O., Ishikawa, H., Tosaka-Shimada, H., \& Atsumi, S. (1999). Exocytotic Secretion of Toxins from Macrophages Infected with Escherichia coli O157. Cell Structure and Function, 24, 247-253.

Soncini, F. C., Vescovi, E. G., \& Groisman, E. A. (1995). Transcriptional autoregulation of the Salmonella typhimurium phoPQ operon. Journal of Bacteriology, 177(15), 4364-4371.

Song, W., Wang, F., Savini, M., Ake, A., di ronza, A., Sardiello, M., \& Segatori, L. (2013). TFEB regulates lysosomal proteostasis. Human Molecular Genetics, 22(10), 1994-2009. http://doi.org/10.1093/hmg/ddt052

Sridhar, S., \& Steele-mortimer, O. (2016). Inherent Variability of Growth Media Impacts the Ability of Salmonella Typhimurium to Interact with Host Cells. PLoS ONE, 1-14. http://doi.org/10.1371/journal.pone.0157043

Stanley, A. C., \& Lacy, P. (2010). Pathways for cytokine secretion. Physiology (Bethesda, Md.), 25(4), 218-29. http://doi.org/10.1152/physiol.00017.2010

Tattoli, I., Sorbara, M. T., Vuckovic, D., Ling, A., Soares, F., Carneiro, L. A. M., ... Girardin, S. E. (2012). Article Amino Acid Starvation Induced by Invasive Bacterial Pathogens Triggers an Innate Host Defense Program. Cell Host and Microbe, 11(6), 563-575. http://doi.org/10.1016/j.chom.2012.04.012

Tauber, A. I. (2003). Metchnikoff and the phagocytosis theory. Nature Publishing Group, 4(November).

Thoreen, C. C., \& Sabatini, D. M. (2009). Rapamycin inhibits mTORC1 , but not completely. Autophagy, 5(July), 725-726. http://doi.org/10.1074/jbc.M900301200.treated

Torraca, V., Masud, S., Spaink, H. P., \& Meijer, A. H. (2014). Macrophage-pathogen interactions in infectious diseases : new therapeutic insights from the zebrafish host model. 
Disease Models and Mechanisms, 785-797. http://doi.org/10.1242/dmm.015594

van der Velden, A. W., Lindgren, S. W., Worley, M. J., \& Heffron, F. (2000). Salmonella pathogenicity island 1-independent induction of apoptosis in infected macrophages by Salmonella enterica serotype typhimurium. Infection and Immunity, 68(10), 5702-9. http://doi.org/10.1128/IAI.68.10.5702-5709.2000.Updated

Vega-rubin-de-celis, S., Peña-llopis, S., \& Konda, M. (2017). Multistep regulation of TFEB by MTORC1. Autophagy, 13(3), 1-9. http://doi.org/10.1080/15548627.2016.1271514

Vural, A., \& Kehrl, J. H. (2014). Autophagy in Macrophages: Impacting Inflammation and Bacterial Infection. Scientifica, 2014(April), 1-13. http://doi.org/10.1155/2014/825463

Warrington, R., Watson, W., Kim, H. L., \& Antonetti, F. R. (2011). An introduction to immunology and immunopathology. Allergy, Asthma \& Clinical Immunology, 7(Suppl 1), S1. http://doi.org/10.1186/1710-1492-7-S1-S1

Wee, D. H., \& Hughes, K. T. (2015). Molecular ruler determines needle length for the Salmonella Spi-1 injectisome. Proceedings of the National Academy of Sciences of the United States of America, 112(13), 4098-4103. http://doi.org/10.1073/pnas.1423492112

Weichhart, T., Hengstschläger, M., \& Linke, M. (2015). Regulation of innate immune cell. Nature Publishing Group, 15(10), 599-614. http://doi.org/10.1038/nri3901

Will, W. R., Bale, D. H., Reid, P. J., Libby, S. J., \& Fang, F. C. (2014). Evolutionary expansion of a regulatory network by counter-silencing. Nat Commun, 5. Retrieved from http://dx.doi.org/10.1038/ncomms6270

Wing, H. J., Yan, A. W., Goldman, S. R., \& Goldberg, M. B. (2004). Regulation of IcsP, the Outer Membrane Protease of the Shigella Actin Tail Assembly Protein IcsA, by Virulence Plasmid Regulators VirF and VirB. Journal of Bacteriology, 186(3), 699-705. http://doi.org/10.1128/JB.186.3.699-705.2004

Wisner, A., Desin, T., White, A., Potter, A., \& Köster, W. (2012). The Salmonella Pathogenicity Island-1 and -2 Encoded Type III Secretion Systems. (Y. Kumar, Ed.)Salmonella - A Diversed Superbug. In Tech. Retrieved from http:/www.intechopen.com/books/salmonellaa-diversified-superbug/the-salmonella-pathogenicity-island-1- and-2-encoded-type-iiisecretion-systems

Wu, J., Pugh, R., Laughlin, R. C., Andrews-polymenis, H., Mcclelland, M., Bäumler, A. J., \& Adams, L. G. (2014). High-throughput Assay to Phenotype Salmonella enterica Typhimurium Association, Invasion , and Replication in Macrophages. JOVE, (August), 17. http://doi.org/10.3791/51759

Zhao, W., Moest, T., Zhao, Y., Guilhon, A.-A., Buffat, C., Gorvel, J.-P., \& Méresse, S. (2015). 
The Salmonella effector protein SifA plays a dual role in virulence. Scientific Reports, 5 , 12979. http://doi.org/10.1038/srep12979

Zhou, D., \& Galán, J. (2001). Salmonella entry into host cells : the work in concert of type III secreted effector proteins. Microbes and Infection, 3, 1293-1298. 